\title{
Child Sleep and Mother Labour Market Outcomes ${ }^{1}$
}

\author{
Joan Costa-Font ${ }^{2}$ and Sarah Fleche ${ }^{3}$
}

\begin{abstract}
We show that sleep deprivation exerts strong negative effects on mothers' labour market performance. To isolate variations in maternal sleep, we exploit unique variations in child sleep disruption using a UK panel dataset that follows mother-child pairs through time. We find that sleeping one hour less per night on average significantly decreases maternal labour force participation, the number of hours worked and household income. We identify one mechanism driving the effects, namely the influence of maternal sleep on selection into full-time versus part-time work. Increased schedule flexibility for mothers with sufficient tenure mitigates the negative effects of sleep deprivation.
\end{abstract}

JEL Codes: J13, J22, I18, J28

Keywords: child sleep, sleep, maternal employment, working hours, workplace flexibility, ALSPAC

\footnotetext{
${ }^{1}$ A previous version of the paper was circulated under the title "Parental Sleep and Employment: Evidence from a British Cohort Study". We are grateful to the participants of the 2017 Royal Economic Society conference in Bristol, and seminar participants at the University of Rome Tor Vergata, IZA institute in Bonn, and University Paris-Dauphine and in particular Dan Hamermesh, Eric Bonsang, Barbara Petrangolo, Gabrielle Fack, Elise Huilery, Joachim Jarreau, Brigitte Dormont, Clement Bosquet, Berkay Ozan, Sebastian Sneider, Colin Espie, Sophie Bostock, Christopher Barnes, Benjamin Elsner, Tomasso Coloussi, Ahmed Elsayed, Sinem Ayham, Arabelle Krausse, Milena Nikolova, Nico Pestel, Eric Somer and Amelie Schiprowski for their comments and suggestions to an earlier version of the paper. This study uses ALSPAC data. We are extremely grateful to all the families who took part in this study, the midwives for their help in recruiting them, and the whole ALSPAC team, which includes interviewers, computer and laboratory technicians, clerical workers, research scientists, volunteers, managers, receptionists and nurses. The UK Medical Research Council and the Wellcome Trust (Grant ref: 102215/2/13/2) and the University of Bristol provide core support for ALSPAC. This research was specifically funded by the US National Institute on Aging (Grant R01AG0400640), the John Templeton Foundation and the What Works Centre for Wellbeing. Ethical approval for the study was obtained from the ALSPAC Ethics and Law Committee and the Local Research Ethics Committees.

${ }^{2}$ Department of Health Policy, London School of Economics and Political Science (LSE). Houghton Street WC2A 2AE. IZA Bonn and CESIfo, Munich. Email: j.costa-font@lse.ac.uk

${ }^{3}$ Department of Economics, Aix-Marseille University - CNRS, EHESS, Centrale Marseille, Aix-Marseille School of Economics - and CEP, London School of Economics. E-mail: sarah.fleche@univ-amu.fr
} 


\section{Introduction}

Working mothers of small children struggle with keeping a work-life balance, which impacts negatively their wellbeing and the quality of resting time. According to a recent study in the UK, mothers getting six or less hours of sleep a night, are so exhausted while dealing with the conflicting demands of working life and motherhood, that $56 \%$ feel depressed and $82 \%$ admit that the lack of sleep affects their performance and output at work. ${ }^{4}$ This is because sleep is an essential human need associated with both good physiological and cognitive functioning. Paradoxically, the extent to which sleep deprivation hampers parental economic activity has received very limited attention in economics research so far. The purpose of this paper is to study the effects of child-related sleep deprivation on mothers' labour market outcomes both in the short-run, as well as on mothers' labour market careers in the longer-run.

Sleep is often overlooked in economics models despite its obvious restorative effects on human health, alongside its influence on brain plasticity and feelings of well-being (Siegel, 2005; Franck, 2006). Failing to get enough sleep can give rise to chronic diseases associated with hypertension, diabetes, depression and obesity, as well as a reduced quality of life (Barnes and Wagner, 2009; Caruso et al., 2006; Scott and Judge, 2006). ${ }^{5}$ Sleep-deprived individuals are more likely to make impulsive decisions, and the prefrontal cortex - which has proven to be critical for executive functioning - is found to be vulnerable to a lack of sleep (Harrison and Stone, 2000). Similarly, a meta-analysis of existing research suggests that sleep deprivation strongly impairs cognitive and motor performance (Pilcher and Huffcutt, 1996; Killgore 2010). Sleep deprivation, even when moderate, can be detrimental to work performance and this can translate into earnings, consistently with recent evidence (Gibson and Shrader, 2018).

The fundamental challenge in estimating sleep deprivation effects is that sleep patterns are not exogenous to individual economic performance. The existing literature has focused on time use surveys and repeated cross-sections, which makes it hard to isolate the causal effects of sleep deprivation from confounding factors and reverse causality (e.g. working individuals reducing their amount of sleep). In this article, we uniquely rely on a very rich UK longitudinal dataset, the Avon Longitudinal Study of Parents and Children (ALSPAC), that followed a sample of 14,000 families and collected information on both maternal and child sleep patterns

\footnotetext{
4 “Working mums: Are you struggling to cope?”, BBC news, April 2002

5 These studies also show a significant relationship between sleep deprivation and cancer as well as increased mortality.
} 
nearly every year since child's birth up to age $12 .{ }^{6}$ Designed by public health researchers, this dataset provides us very precise information on child sleep, including whether the child wakes up at night, sleep time and day sleep, as well as child sleeping routines and environmental triggers of sleep quality. Following mother-child pairs through time and controlling for unobserved heterogeneity thanks to mother-child fixed effects, this allows us to exploit longitudinal variations in child sleep disruption as an instrument for maternal sleep duration (adjusted for child's age fixed effects, health, household composition and environmental triggers).

To minimise potential biases due to confounding factors, our empirical strategy proceeds in three steps. First, we consider only differences in sleep patterns within mother-child pairs through time, rather than between them. This is to ensure that time-invariant confounders (such as genetic predispositions towards poor sleep, education, mother's ability to improve the sleep of her child or persistent mother reporting bias) are not driving our results. Second, the ALSPAC data allow us to isolate maternal sleep deprivation effects from an extensive set of time-varying factors including family-level shocks, parenting style, mother's and child's stress, to which extent mother is determined to invest in her career, and father characteristics. Third, we make use of the estimated relationship between observed characteristics and our variables of interest to show that selection on unobservables is unlikely to fully explain our results. ${ }^{7}$ In attempt to address the issue of reverse causality, the panel nature of the data also allows us to perform simple falsification tests using previous years' mother sleep patterns and labour market outcomes and investigate the relationship with current child sleep.

Our first results demonstrate that there is a significant relationship between the number of times a child wakes up at night and mother's sleep duration. We find that a one-unit increase in the number of times a child wakes up at night leads to a reduction in the mother's average duration of sleep by a bit less than 10 minutes per night. Increased child sleep disruption reduces the probability of both maternal and paternal sleep duration, although the effect on maternal sleep is more than twice that on paternal sleep.

We then assess the impact of child-related sleep deprivation on mothers' employment, working-time decisions and income. Using the variations in child sleep interruption over time as an instrument for changes in mother's sleep duration, we estimate the effect of sleep on

\footnotetext{
6 Throughout the article we restrict the sample to families with children under the age of 12 for which we have information on child sleep. We also perform robustness checks restricting the sample to families with children above 2 and below 5 for which factors driving sleep behaviours are arguably more exogenous.

${ }^{7}$ We implement Oster (2017)'s methodology to evaluate the selection on unobservables in our results.
} 
mothers' economic performance to be substantial. Improving the mother's average nightly sleep duration by half-an-hour ${ }^{8}$ would increase her participation in the labour market by 2.5 percentage points, her number of hours worked by $7 \%$, household income ${ }^{9}$ by $4.95 \%$ and her job satisfaction by 0.01 standard deviations.

Sleep interruption can result from children's sleep patterns above and beyond parents' ability to get their children into a sleeping routine, and hence, entails some degree of uncertainty that makes it hard to predict. As such, child-related sleep deprivation is an important source of variation in parental sleep duration during the child-bearing time that is worth exploiting. Also, the negative impact of being a mother on the quality of sleep starts during the pregnancy and can last well-beyond kindergarten. In our data, almost $40 \%$ of children aged 2-5 are still getting their parents up in the night, whilst this is only the case for $20 \%$ of children aged 5-8. Looking at the effect on mothers' employment and household income five years later, we find that mothers with children who had sleeping problems are still less likely to work and have lower household income than mothers with children who had normal sleeping routines. Five years later, these mothers have household incomes, which are 3.8\% lower compared to mothers who slept 30 minutes more on average per night.

Investigating potential channels, we find that changes in how mothers value work relative to other goals in life does not account for these negative effects on mothers' labour market outcomes. Instead, we show that a reduction in mother sleep duration is associated with (i) a higher probability to experience problems at work, (ii) increased difficulties to deal with the demands of working life and motherhood, and (iii) a shift from full-time to part-time jobs. Also, we find that the negative effects of child-related sleep deprivation are smaller for mothers with less responsibilities (only one child), higher educational qualifications, and better organisation skills. These results suggest that some women have greater ability to adapt to poor child sleep. Increasing access to flexible working hours could attenuate the negative effects of child-related sleep deprivation. To illustrate this, we draw on the UK Employment Rights Act 1996, which entitled the right to request flexible working to parents with 26 weeks' continuous employment. Using a triple difference strategy, we show that the UK Employment Right Act 1996 mitigated

\footnotetext{
${ }^{8}$ We choose to discuss the results in terms of 30-minutes sleep changes (instead of one-hour changes) as the range of identified variations in mother sleep duration from the first-stage regressions is rather small (from 0 to 40 minutes).

${ }^{9}$ Note that the ALSPAC data do not provide information on mother individual income.
} 
the impact of child-related sleep deprivation for mothers of young children who were eligible to flexible working (either hours, times or location of work). ${ }^{10}$

The general message of this analysis is that sleep is a major determinant of employment outcomes that needs more attention in designing employment policies. The number of hours the average person sleeps has declined over the past century, ${ }^{11}$ and we still ignore its effects on economic activity and economic performance. The estimated effect of sleep in our study can be attributed to changes in child sleep. To our knowledge, this is the first paper to establish a link between child sleep and mothers' labour market outcomes. Over the last decades, women have experienced substantial gains on the labour market. That is, the gender gap in labour force participation and earnings have both reduced. Yet, substantial gender gaps remain (Blau and Kahn, 2006). When mothers return to work after childbirth, they are more likely to work below their potential and work fewer hours. This downgrading effect is likely to persist over time, as the birth of a child reduces mothers' chances of getting promotions and pay rises and their wages plateau (Waldfogel, 1995; 1997). In contrast, men's wages continue growing rapidly at this point in the life cycle (particularly for the highly educated, Costa Dias et al., 2016). The results we present in this article support the view that child-related sleep deprivation is a factor that limits convergence on the labour market outcomes for working women of young children.

The rest of this paper has the following structure. The next section reviews the related literature. Section III presents the data. Section IV reports OLS regressions of mother sleep duration on child sleep duration and child awakening. Section V describes the relationship between mothers' economic performance and their duration of sleep. Section VI investigates the robustness checks of the results. Section VII tests for long-term effects, mechanisms, heterogeneous effects and the role of public policies. Section VIII concludes.

\footnotetext{
${ }^{10}$ In the UK, mothers who have children under 17 and who have worked 26 continuous weeks or more are allowed to request flexible working under the Employment Rights Act 1996, which employers in turn must address in a “reasonable manner". https://www.gov.uk/flexible-working/overview

${ }^{11}$ In the UK, 33\% get 5-6 hours per night in 2017, compared to $27 \%$ in 2010 . According to NHS guidelines, most adults require between 6 and 9 hours per night in order to feel refreshed and to function well both mentally and physically.
} 


\section{Literature Review}

The current economics literature on sleep is still at its infancy. Drawing on the tradition of Becker (1965)'s and Grossman (1972)'s models on allocation of time and their application to health, a seminal work by Biddle and Hamermesh (1990) developed an optimal model of time to study sleep. Although standard economic models implicitly assumed that individuals are endowed with a fixed amount of time allocated between work and leisure, Biddle and Hamermesh (1990) allowed the amount of sleep time at an individual's disposal to vary over time. These variations in sleep time could then affect the choice between work and leisure. In their empirical work, they used a cross section of time-use survey data and estimated that a onehour increase in paid work reduces sleep by 10 minutes. More recently, Hamermesh et al. (2008) examined how cues such as TV programs and sunlight affect sleep and coordination.

Biddle and Hamermesh (1990)'s model implies that (i) sleep duration affects the amount of time devoted to market work and (ii) higher labour productivity raises the opportunity cost of sleep time. A handful of studies have examined the latter relationship, i.e. the effect of income and education, financial market performance, and employment on sleep (Gardner et al., 2010; Kamstra et al., 2000; Szalatonai, 2006; Brochu et al., 2012; Bonke, 2012; Antillon et al., 2014; Ásgeirsdóttir and Ólafsson, 2015). Other studies have focused on the nexus between socioeconomic characteristics and household-derived sleep deprivation (Arber et al., 2009; Carrell et al., 2011; Gardner et al., 2010). However, the former relationship, i.e. the influence of sleep duration on labour market performance, has barely been studied. Our paper, to the best of our knowledge, is the first to study the effect of child-related sleep deprivation on mother economic activity. ${ }^{12}$

Particularly relevant for our current paper is the scarce literature which attempts to capture a causal link between health behaviours, sleep duration and wages. Only one paper deals with the endogeneity of sleep by using an instrumental variables approach as we do here. Gibson and Shrader (2018) instrument for sleep by using the short and long-term sunset times. Using time use diaries from the United States, they demonstrate that later sunset time reduces worker sleep and wages. Their empirical strategy relies on location-level variations and therefore cannot be interpreted as individual effects. Our paper differs from this study by drawing on individual variations in sleep quality. More generally, we rely on micro-longitudinal data, and in contrast to previous studies, we do not employ cross-sectional time-use surveys.

\footnotetext{
12 Our paper is also related to the medical literature that investigates the impact of sleep deprivation on cognitive and task performance (see Van Dongen and Dinges (2005) and Banks and Dinges (2007) for a review).
} 
Finally, the institutional context of UK allows us to uniquely study the role of public policies on the economic returns to sleep. Several policies have been implemented over the past decades across developed countries to help mother dealing with family and career choices. Key among those are maternity and parental leave systems. Others include access to more flexible working schedules (Blau and Kahn, 2013). Our findings suggest that flexible time schedules do help mothers to mitigate the negative effects of child-related sleep deprivation.

\section{The ALSPAC Data}

We use a unique dataset, the ALSPAC data, which has followed more than 14,000 families from childbirth to age 25. This is a near-census English cohort study, which was primarily designed to investigate environment, genetic, and socioeconomic influences on health and development over the life course. ${ }^{13}$ The study recruited 14,541 pregnant women residing in the Avon area of the UK with expected delivery dates between April 1, 1991, and December 31, 1992. ${ }^{14}$ This corresponds to roughly $70 \%$ of the eligible pregnancies in the area. If we examine the sample characteristics, higher socioeconomic status groups, as well as people of white ethnicity, are slightly over-represented compared to the national population (Boyd et al., 2012). $79 \%$ of mothers in ALSPAC lived in owner-occupied accommodation in 1991, 79\% were married, and 2\% were non-white. In Britain, $63 \%$ of mothers lived in owner-occupied accommodation in 1991, 72\% were married, and 8\% were non-white (1991 census).

Data on Sleep and Labour Market Outcomes. The study includes rich information on parental characteristics and family background as well as indicators of child well-being, physical health and cognitive skills. In particular, the dataset provides precise information on parental and child sleep over time, which have been intensively used by health researchers (see Blair et al., 2012 for a review). In addition, it contains various variables on mothers' employment, working-time decisions, income and job satisfaction, for our purposes. Table 1 provides the descriptive statistics for the key variables of interest distinguishing employmentrelated and sleep-related variables. The sample is restricted to families with children under the

\footnotetext{
13 Please note that the study website contains details for all the data that is available through a full separable data dictionary: http://www.bris.ac.uk/alspac/researchers/data-access/data-dictionary/

1414,541 is the initial number of pregnancies for which the mother enrolled in the ALSPAC study and had either returned at least one questionnaire or attended a "Children in Focus" clinic by 19/07/99. Of these initial pregnancies, there was a total of 14,676 foetuses, resulting in 14,062 live births and 13,988 children who were alive at 1 year of age.
} 
age of 12 (for which we have information on child sleep). This gives us a sample size of roughly 12,000 families. After age 12, the survey questions on child sleep are no longer available.

Child sleep information is available for a number of years since childbirth: at 1, 6, 18, 30, 42, 57, 69, 81, 108 and 134 months. The questions include the time (24-hour clock) at which the child "normally" goes to bed in the evening and wakes in the morning on an "average" weekday (see Appendix $\mathrm{C}$ for a detailed description of the variables). From this response, nighttime sleep durations are calculated. ${ }^{15,16}$ Similarly, the ALSPAC survey includes a question on the probability and the number of times a child wakes up at night: "How often does your baby/child wake at night?" Never - Occasionally - Most nights - Every night - More than once per night (How many times?). One might prefer these measures since they explicitly refer to sleep disruption. On the other hand, they may be noisier measures of child sleep than the child average duration of sleep. In row 4, we also document whether the child has a regular sleeping routine as an alternative measure of child sleep. Table A1 in the Online Appendix examines the correlation between the different measures of child sleep used in this paper. Overall, we find significant correlations that suggest that waking up reduces sleep duration and having a sleep routine increases it. Note that if mother's sleep is affected by the frequency of child wakings, she might have a natural bias in misreporting child sleep disruption when she does not get enough sleep. ${ }^{17}$

We use several variables to capture mother sleep. Our main variable, reported in the fifth row of Table 1, is an average of mother's sleep duration. The question is as follows: "How many hours of sleep do you get altogether during an average night?". On average, mothers sleep about 7 hours per night. We use the continuous variable for our main specification. However, one might also want to consider different categories: whether the mother sleeps less than 6 hours, between 6 and 7 hours or more than 7 hours per night. These categories are appropriate for our purposes since the focus here is on differences in economic performance originating from sleep deprivation. Specifically, we wish to establish if the mother has enough

\footnotetext{
${ }^{15}$ Using fluctuations on a yearly basis is not ideal. We are aware that such aggregated data (with potentially a lot of averaging in the reporting) could bias our estimates towards zero. Unfortunately, the ALSPAC data do not provide us information within shorter-time intervals.

16 Note that time use questions are usually included in a full-time diary with questions about particular uses and reported to an interviewer. From this point of view, ALSPAC does not adhere to these practices. We are aware that this could generate reporting biases (see Hamermesh et al., 2005; Schober and Conrad, 1997).

17 To deal with this issue, we would like to be able to compare mother's reports with father's and child's reports. Unfortunately, this is not possible in this dataset. See Section VI for further discussion.
} 
sleep in order to be productive and not only how many hours the mother sleeps. The next row of Table 1 gives an alternative relevant measure, which is whether the mother feels she has enough sleep (from 0 to 1 ). We expect our notion of getting enough sleep to correspond to the number of hours slept, but the threshold may differ across individuals. ${ }^{18}$ Therefore, it is interesting to consider both types of measures of sleep. Fortunately, the ALSPAC data also include questions on father sleep, reported by the father himself. ${ }^{19}$ We use two variables to capture father sleep: average of father's sleep duration and whether the father feels he has enough sleep.

The following six rows report measures of parents' employment outcomes, which we use for measuring economic performance. The first is a measure of employment status (whether the mother/father currently works) and the second is a measure of part-time versus full-time jobs. In our sample, $59 \%$ of mothers work and $84 \%$ of fathers work. $23 \%$ of the mothers work parttime. Interestingly, we are comparing individuals for whom having children is a choice. Hence, we expect individuals in our sample to be more comparable to the extent that they are all parents. In the following rows, we give the mean and the standard deviation of the number of hours worked. The question included in ALSPAC refers to the actual hours currently worked per week by the mother. The second-to-last row gives information on the annual household income (in 2008 prices). The final row gives a measure of job satisfaction, reported on 0-1 scale, which is our measure of wellbeing at work. In our sample, $66 \%$ of mothers report being satisfied at work..$^{20}$ Note that labour market choices are usually joint at the household level. It is therefore quite important, both from an economics and policy perspective, to consider impacts not only on maternal but also on paternal sleep and labour market outcomes since they are available.

\section{[Table 1 about here]}

Descriptive Statistics on Child Sleep. The first interesting fact is that there are large variations in child average duration of sleep and the probability that child wakes up at night.

\footnotetext{
18 The correlation between the number of hours slept and getting enough sleep for mother is 0.462 . Appendix Figure A1 shows a scatterplot of the share reporting adequate sleep against reported sleep duration. We see that as mother sleeps more hours, she is also more likely to report having enough sleep.

${ }^{19}$ Note that father here refers to the mother's partner living in the household at time $t$. It could be someone different than the biological father.

${ }^{20}$ Job satisfaction is positively correlated with the number of hours worked and income in our sample.
} 
According to Table 1, the standard deviation is 1.24 for a child's average duration of sleep and 0.45 for the probability that the child wakes up at night. Children between 0 and 24 months sleep a little more than 11 hours. This pattern decreases over time and by age 8 , children sleep about 10 hours every 24 hours. As expected, we also find that over time children are more likely to adjust to a sleeping routine and by age $8,94 \%$ of children already have a sleeping routine (see Appendix Figures A2 and A3). These findings are in line with other studies analysing the ALSPAC data (see Blair et al., 2012).

We can also examine how child sleep disruption evolves over time. Figure 1 depicts changes in the number of times the child wakes up at night relative to the first year of life, by age. We find a spike in the number of times the child wakes up at night between 2-5 years of age which is in line with findings of a recent review of observational studies (Galland et al., 2012). In our sample, $40 \%$ of children wake up at night between 2-5 years of age, and still $20 \%$ of children wake up at night between 5-12 years of age. Night wakings are common in infancy and early childhood. Several factors influence these wakings and children's ability to return to sleep unaided plays a crucial role in determining whether or not wakings will persist and become problematic. Arguably, the frequency of night wakings and parents' reported quality of child sleep are positively correlated. ${ }^{21}$

\section{[Figure 1 about here]}

At a given age, sleep patterns also do vary. Sleep-wake patterns are driven by a mix of several factors, including environmental, behavioural and social factors, but also biological processes. They can vary widely across children and are hard to predict. Appendix Figure A4 shows that the average child duration of sleep varies roughly from 8 to 16 hours across 2-yearsolds. Similarly, the number of times the child wakes up varies from 0 to 4 (Appendix Figure A5). The variation narrows with age, but even at 12, the sleep duration varies from 8 to 11 hours. There is a significant correlation between child average duration of sleep at a given age and each adjacent age, but this correlation steadily weakened as we look at ages further apart (Appendix Table A2). Moreover, children who tend to wake up frequently at an individual

\footnotetext{
${ }^{21}$ Palmstierna et al. (2008) investigate what influence parent-reported child sleep using data from parents of around 10,000 children from birth to age 5 in a cohort questionnaire study in Sweden. They find that reports of frequent night wakings and low sleep quality are strongly associated with each other within and between the age groups.
} 
timepoint are not systematically the same who wake up frequently at other timepoints (Appendix Table A3). ${ }^{22}$

These large and quite unpredictable variations in child sleep interruption can be very detrimental to parents' sleep. They diminish both sleep duration and cause fragmentation, which impacts on mothers' mood and attention (Kahn et al., 2014). In our sample, $72 \%$ of mothers of one-year-olds declare feeding their baby when waking up at night, and $40 \%$ cuddle them. In addition, $65 \%$ of mothers have already taken their baby into bed after a night waking. Accordingly, there are large variations in mother's sleep time. According to Table 1, mothers sleep on average 6.9 hours per night. Yet, 13\% sleep less than 6 hours per night on average. $54 \%$ sleep between 6 and 7 hours and 33\% sleep more than 7 hours per night. ${ }^{23}$ These figures are consistent with general patterns of sleep reported by the NHS. Note that $1 \%$ of mothers report sleeping less than 2 hours in ALSPAC. Excluding these mothers from our sample gives us a sample mean of 6.8 ( $\mathrm{std}=1.40)$. Mothers who report being sleep-deprived (sleeping 6 hours or less per night) tend to be slightly less educated, are less likely to be in couple and report lower health..

\section{Child and Parental Sleep}

In this section, we begin by examining the correlations between child duration of sleep and the number of times the child wakes up at night with maternal sleep duration (the first stage of our IV strategy). The estimated equation is as follows:

(1) $\mathrm{MS}_{\mathrm{it}}=\delta+\mu \mathrm{CS}_{\mathrm{it}}+\beta \mathrm{CI}_{\mathrm{it}}+\mathrm{Z}_{\mathrm{it}} \lambda+\rho_{\mathrm{i}}+\mathrm{u}_{\mathrm{it}}$

\footnotetext{
22 There is apparently remarkably little evidence on the determinants of individual differences in child sleep duration. To determine the relative contributions of genetic and environmental factors on daytime and nighttime sleep duration in childhood, some studies have used twin data. They reveal a moderate contribution of genes to explain the variations in sleep duration (approximately 30\%). See Touchette et al. (2013), Dionne et al., (2011), Gehrman et al., (2011), and Moore et al., (2011). Overall, these studies conclude that substantial individual variations remain at all ages (Iglowstein et al., 2013; Acebo et al., 2015). Other studies have examined sleep duration in cohorts of children across early childhood. Using the ALSPAC data, Blair et al. (2012) for example identify demographic characteristics associated with sleep duration. They find that girls sleep consistently longer than boys. Children from low-income families go to bed later and wake up later, but there is little difference in total sleep duration.

${ }^{23}$ Appendix Figure A6 plots the raw distribution of mother's sleep.
} 
where $\mathrm{MS}_{\mathrm{it}}$ is our measure of sleep of mother of child i at age t. $\mathrm{CS}_{\mathrm{it}}$ is our measure of child sleep duration, and $\mathrm{CI}_{\mathrm{it}}$ is our measure of child sleep interruption. $\mathrm{Z}_{\mathrm{it}}$ is a vector of covariates that include a wide range of time-varying child and mother characteristics, including child's age dummies, child's health, mother's general health, mother's mental health, ${ }^{24}$ the number of children in the household, whether mother is separated, and environmental triggers (noise and whether child shares bedroom). $\rho_{\mathrm{i}}$ are mother-child fixed-effects. Standard errors are clustered on mother-child pairs. ${ }^{25}$

Our source of identification corresponds to deviations in child sleep disruption and child sleep duration of sleep, adjusted for child's age dummies and other covariates. ${ }^{26}$ Because child sleep disruption and child sleep duration can be both detrimental to parents' sleep, it is important to consider both effects in our regressions. Conditioning on age fixed effects better isolates random variations in sleep. Moreover, because these deviations could be driven by child's health problems, which could also affect mother's sleep, we must control for the direct effect of child's health. If there are multiple children in the household and sleep is correlated among them, then the sleep of the observed child will potentially be capturing the poor sleep of other children. Not controlling for the number of children in the household could potentially generate spurious correlations. ${ }^{27}$ Noise in the house and sharing a room can increase the probability of (and the number of times) a child wakes up at night and reduce the probability of a child adopting a sleeping routine. The quality of the sleep environment also matters because it is directly correlated with maternal sleep and potentially with socio-economic characteristics of the household. Some maternal characteristics are important: mothers with bad health or who are anxious/depressed are likely to sleep less. If mothers are nervous, their children are also more likely to be nervous and report bad sleeping quality. Finally, mother-child fixed effects allow us to control for any unobserved heterogeneity across mother-child pairs, including

\footnotetext{
${ }^{24}$ Child health is measured as follows: "How would you assess the health of your child in the past year?" Very healthy - few minor pbs - sometimes ill - hardly very well. To measure mother's general health, we rely on the following question: "Which of the following would you say describes your health now?" Fit well - mostly well and healthy - often feel unwell - hardly every feel well. The ALSPAC data provide information on the Edinburg post-natal depression score to assess mother's mental health. See Appendix C for a detailed description of all the variables.

25 As shown in the Online Appendix, Appendix Table A14, our results are robust to two-way clustering on motherchild and year.

${ }^{26}$ Note that we cannot include sibling-fixed effects as only one child per family is observed in the ALSPAC data.

27 As shown in Appendix Table A9 our results are robust to restricting our sample to mothers with only one child.
} 
genetic propensity for interrupted sleep, mother ability to improve child sleep and mother persistent reporting bias.

We begin by graphically examining the relationship. Figure 2 plots mother's average duration of sleep against the number of times the child wakes up at night. To construct this scatter plot, we first average the number of times the child wakes up at night by mother-child pairs. We then plot the means of the y-variable within each average against the mean value of the number of times the child wakes up at night within each mother-child pair. As expected, there is a strong relationship between the number of times the child wakes up at night and the mother's average duration of sleep. This indicates that mothers who have a child with good sleeping routines and who seldom wakes up at night, sleep longer on average than mothers who have a child with sleeping problems. To interpret the magnitude of the impact, an increase by one-unit in the number of times the child wakes up at night decreases the average duration of mother sleep by $7 \%$, relative to a sample mean of $6.9(\mathrm{std}=1.38)$. We find in addition, that the association is more heterogeneous after the first wake up given that the reason and duration of each night time wake up becomes more varied after the first awakening (e.g. sickness, nightmares, sleep problems, toileting, etc.).

\section{[Figure 2 about here]}

We then run OLS regressions of equation (1) including a wide range of controls for child and mother characteristics as well as mother-child fixed effects. The results are presented in Table 2. Appendix Table A4 reports control coefficients. Columns (1) and (2) use mother's hours slept as the dependent variable and confirm that there is a strong correlation between the number of times the child wakes up at night and the mother's average duration of sleep. A oneunit increase in the number of times a child wakes up at night decreases the mother's hours slept by 0.105 (6.3 minutes) and increases the probability of sleeping less than 6 hours per night by 2.3 percentage points. Note that the estimates are much smaller than the slope in Figure 2 as we control for a range of child and mother characteristics as well as mother-child fixed effects (see Appendix Table A5 for the cross-section estimates). Finally, column (3) indicates that when a child sleeps longer, the mother is more likely to feel that she is getting enough sleep. Similarly, when a child wakes up at night, the mother is more likely to feel that she is not getting enough sleep.

[Table 2 about here] 
We also perform the analysis by first-differencing mother sleep duration and child sleep quality to explicitly control for child-specific trends. Using this model corrects for any linear trend in unobserved heterogeneity across mother-child pairs as we keep controlling for motherchild fixed effects. Column (4) indicates that the results are robust to this alternative specification, although the estimates vary. The coefficient on the number of times the child wakes up at night is now 0.036 , suggesting that a one unit-increase in the number of times a child wakes up at night decreases the mother's hours slept by 2.2 minutes and an hour increase in child sleep duration increases the mother's hours slept by 5.9 minutes.

Beyond the inclusion of child-specific trends, we further check the exogeneity of observed child sleep patterns using a placebo test. A threat to our identification strategy would be that mother sleep patterns are systematically associated with child sleep due to omitted factors (e.g. genetic predispositions to poor sleep, social cues, reporting bias in sleep or mothers' ability to keep their children to a sleeping routine). Considering mother's sleep duration three years prior - thereby guaranteeing that child sleep patterns could not have possibly affected mother sleep duration at that time - column (5) shows that there is reassuringly no effect of child sleep duration and the number of times the child wakes up on previous mother's sleep. As we do not observe maternal sleep patterns before child birth, note that this specification implies that we only consider children aged $3+.^{28}$

The remaining specification examines the effect of child sleep disruption on father's sleep. As with mother, we find that child sleep duration (the number of times the child wakes up at night) increases (reduces) the father's average duration of sleep. Yet the effect on paternal sleep is half the effect on maternal sleep when comparing with column (1). ${ }^{29}$ Interestingly, fathers are less affected when child wakes up at night. This is consistent with the fact that, in our sample, $6.20 \%$ of fathers report waking up at night to feed the child, while the proportion is $63.69 \%$ for mothers. ${ }^{30}$

\footnotetext{
${ }^{28}$ As the number of times the child wakes up at night spikes between 2-5 years of age, we are pretty confident that substantial variation in child sleep patterns for children aged $3+$ remains.

${ }^{29}$ The coefficient on child's sleep duration is 0.01 (compared to 0.03 for mothers) and -0.04 for the number of times the child wakes up at night (compared to -0.105 for mothers).

${ }^{30}$ Biddle and Hamermesh (1990) also find heterogeneous effects of having young children on parents' sleep time. They write: "Men's sleep duration is essentially unaffected [by having children], but young mothers' sleep is substantially reduced by the care devoted to young children".
} 


\section{Maternal Sleep and Economic Performance}

We now empirically analyse the effect of mother sleep duration on a number of mother's employment outcomes including labour market participation, working-time decisions, income and job satisfaction. We build on the results of Section IV and construct an instrument for mother sleep based on measures of child sleep during the first 12 years of life. More specifically, we instrument maternal sleep duration by deviations in child sleep disruption and child sleep duration as in equation (1). ${ }^{31}$ Our strategy relies on two hypotheses: First, one can identify significant variations in child sleep over time, which in turn affect mother sleep (see Section IV). Second, conditional on observables and mother-child fixed effects, child sleep is orthogonal to factors that might directly influence mother's employment and labour market outcomes. A threat to the exclusion restriction would be that time-varying unobserved shocks are systematically associated with child sleep disturbance, child sleep duration and mothers' labour market outcomes (e.g. mothers' ability to improve the sleep of their children, mothers' stress levels, family-level shocks, parenting style and choices of child-care use). Although it is hard, if not impossible to rule out the existence of confounding factors that would interfere with our estimates, we provide evidence that our estimates are rather insensitive to the inclusion of an extensive set of time-varying factors (Panels A-F in Table 4). Another evidence is the observation in Panel H of Table 4 of significant reduced-form effects of child sleep interruption and child sleep duration on maternal labour outcomes. We can also make use of the amount of selection on observables as a guide to the amount of selection on unobservables (see Altonji et al., 2005; Oster, 2017). We explore further this question in Section VI. In a nutshell, the insensitivity of the results to our controls and the "modest" association between observables that determine the mother labour market outcomes allow us to conclude that confounding factors cannot possibly explain the entire sleep deprivation effects that we estimate.

The empirical specification we estimate is represented in the following equation:

(2) $\mathrm{Y}_{\mathrm{it}}=\alpha+\beta \mathrm{MS}_{\mathrm{it}}+\mathrm{X}_{\mathrm{it}} \gamma+\mu_{\mathrm{i}}+\varepsilon_{\mathrm{it}}$

\footnotetext{
${ }^{31}$ The first stage regression is the one presented in Table 2, column (1). We also present robustness checks using only child sleep disruption as instrument for mother sleep, controlling for child sleep duration (see Appendix Table
} A12). 
where $\mathrm{Y}_{\text {it }}$ is employment status, the number of hours worked, household income, or job satisfaction of mother of child $i$ at age $t . \mathrm{MS}_{\mathrm{it}}$ is the mother duration of sleep instrumented by child sleep disruption and child sleep duration, $\mathrm{X}_{\mathrm{it}}$ is the same vector of covariates as in equation (1) and $\mu_{\mathrm{i}}$ is a mother-child fixed-effect. Standard errors are clustered on mother-child pairs. The coefficient of interest is $\beta$, the effect of mother sleep duration on her economic performance $\mathrm{Y}_{\mathrm{it} .}{ }^{32}$

Table 3 reports the results of equation (2) for the four different outcomes. We focus on mother sleep duration - although robustness checks for mother sleeping less than 6 hours and mother getting enough sleep are reported in Table A6 of the Online Appendix. In Panel A of Table 3, we perform simple OLS regressions, while Panel B presents the central results of this section and reports two-stage least square (2SLS) estimates of the coefficient of interest, $\beta$ from equation (2). The weak identification tests produce large Kleibergen-Paap statistics $(\mathrm{F}>50)$ that compare favourably to the statistics reported in Stock and Yogo (2005). This allows us to reject the hypothesis of weak instruments for all regressions.

Column (1) shows a robust and significant relationship between mother's sleep duration and the mother's employment probability. In terms of magnitude, the estimate in column (1), Panel B, 0.050, indicates that a 30-minutes increase in mother sleep duration would increase employment by 2.5 percentage points. In column (2), we test the effect of mother's sleep duration on the number of hours worked. The coefficient on mother's average sleep duration is positive and significant, indicating that a 30-minutes increase in maternal sleep duration would increase her number of hours worked by 7\%. In column (3), we use the log of household income as the dependent variable. The coefficient on mother's sleep duration is statistically significant. The estimate in column (3), Panel B, indicates that a 30-minutes increase in mother's sleep duration increases household income by $4.95 \%$. Note that household income is a function of mother's sleep, but also father's sleep (which is also shown to be impacted, although less, by child sleep). Hence these income regressions control for father's sleep and should be interpreted as an effect of sleep on both mother's and father's income. Appendix Table A7 displays the estimation results of our income regression when father's sleep is not controlled for. It also presents our income regression when sleep is aggregated at the household level and instrumented by child sleep. The coefficient of household sleep is slightly reduced but it

\footnotetext{
${ }^{32}$ Covariates include child's age dummies, child health, mother's general health, mother's mental health, the number of children in the household, whether mother is separated, and environmental triggers (noise and whether child shares the bedroom).
} 
remains statistically significant and positive. ${ }^{33}$ Finally, in column (4) of Table 3, we look at the effect of mother's sleep on mother's satisfaction with job (which we expect to pick up potential work-life balance effects of sleep deprivation that are not necessarily reflected in participation, hours worked and income effects). The effect is not statistically significant in both Panels A and $B$. There are a number of potential reasons why the effect on job satisfaction is insignificant. First, mothers satisfied with their job are more likely to sleep less than mothers not satisfied with job, which could raise even more the reverse causality issue. In addition, the measure of job satisfaction is reported by the mother herself and can be subject to large measurement errors as the scale goes from 0 to 1 .

\section{[Table 3 about here]}

Overall, the results in Table 3 are consistent with the existence of a strong and significant effect of mother's sleep on several employment outcomes including employment, working-time decisions, household income and job satisfaction. The 2SLS estimates are larger than the OLS estimates reported in Table 3, Panel A. This suggests that the OLS estimates were downward biased. Does the 2SLS estimate make quantitative sense? To better compare magnitudes across columns, Appendix Table A8 replicates the estimation results using the same sample across specifications 1-3. The results do exhibit some changes but remain in the same range. ${ }^{34}$ Overall, the results suggest large effects of mother sleep on employment outcomes, consistent with available evidence from the sleep-labour literature. For example, Gibson and Shrader (2018) find that sunset time one hour later decreases long-run wages by $5 \%$. Similarly, Biddle and Hamermesh (1990) find that a one-hour difference in sleep duration is associated with a $15 \%$ difference in the number of hours worked. Szalontai (2006) finds that a one hour-increase in sleep duration is the predicted difference in sleep time for someone earning an average wage and an individual in the highest income group. ${ }^{35}$ In practice, the presence of measurement errors complicates this interpretation. But overall, the estimates imply a not implausibility large effect of child-related sleep deprivation on mother economic performance.

\footnotetext{
33 Appendix Table A7 also displays the effect of father sleep on the father's probability to work and household income. The coefficients are statistically significant using 2SLS.

${ }^{34}$ We choose not to use the same sample across specifications 1-3 in the main analyses as this would decrease by $20 \%$ the size of specification 1 sample.

${ }^{35}$ For comparison, the effect of an additional year of schooling would have the same wage return as an increase in average sleep duration by 2 hours (see Angrist and Krueger, 1991; Card, 1995).
} 


\section{Robustness Checks}

The previous sections show that child-related sleep deprivation decreases mother labour force participation, the number of hours worked, and household income. However, given that the identification of the effect of mother sleep on employment outcomes can be affected by several biases, this section is devoted to considering such potential biases one by one alongside several robustness checks.

We begin by considering the inclusion of various additional controls influencing child sleep, such as family-life events, new household composition, parenting style and father's characteristics, which might also directly influence mother's employment outcomes. Overall, we find that our results change remarkably little with the inclusion of these variables. In Panel A of Table 4, we first investigate the effects of family-life events such as the presence of a new parent, a new sibling, hospital visit, child is taken into care, the presence of a new carer, child, started crèche, loss of a parent, loss of a sibling, loss of a close friend, whether mother has problem with law, whether parents divorced, moved house, father lost his job, and whether pet died. This has little effect on our 2SLS estimates. For example, the estimate of the effect of sleep duration on employment is 0.050 (s.e. $=0.021$ ) without controlling for family life events and again 0.041 (s.e. $=0.021$ ) with family life events. The effects on hours worked and $\log$ household income are now 0.119 (s.e. $=0.060)$ and 0.094 (s.e. $=0.019)$, respectively.

Similarly, the presence of other children can influence child sleep, mother sleep and mother economic performance. To control for this, in Panel B, we run equation (2) including the number of children in the household, whether there is a new sibling, whether there is a new carer/parent in the household, whether mother has a new partner and whether parents divorced. Again, these controls have small qualitative effect on our main estimates. Note that the coefficient on the number of hours worked is now $12 \%$ instead of $14 \%$ in Table 3 . In Appendix Table A9, we also replicate our results restricting the sample to mothers with only one child. Similar results are obtained. In Panel C, we investigate whether our instruments could be capturing any effect related to father's characteristics. One might argue that child sleep would affect mother's sleep differently according to father's behaviour. Controlling for father's health, father's mental health and father's sleep, our results do exhibit some changes. The coefficient 
on employment is 0.051 . The coefficient on the number of hours worked is now $14.3 \%$ instead of $14 \%$ in Table 3 . Further, the effect on income is $15.4 \%$, instead of $9.9 \%{ }^{36}$

Parenting style is argued to be important for sleep (Mindell et al., 2013). Bedtime and wakeup time, as well as day, sleep significantly influence child sleep. In Panel D, we control for the following variables: the number of hours spent in childcare (commercial carer and nursery), time the child goes to bed, time the child wakes up, and whether there is any sleep during daytime. Also, if mothers who value more work manage to improve their child sleeping routine, it is important to control for mother's attitudes towards work. The ALSPAC data provide information on reasons why working at different points in time. In Panel D, we control for whether mother works for career reasons. Our estimates of the effect of sleep duration on economic performance increase and remain significant. ${ }^{37}$

Finally, in Panel E, we control for additional child characteristics, including child cognitive performance, child emotional health and behaviours. ${ }^{38}$ The estimates of the effect of sleep on mother economic performance remain qualitatively the same. Overall, some deviations from our baseline estimates emerge after controlling for family-level shocks, household composition, father's characteristics, parenting style, and child characteristics altogether (Panel F). The effects of sleep on the probability to work and the number of hours worked are estimated to be slightly higher, while the effect of sleep on income is estimated to be a bit smaller. Overall, we can conclude that the results are consistent with sleep being a significant determinant of mother economic performance, with little effect from family-level shocks, household composition, father's characteristics, parenting style and child cognitive and socio-emotional characteristics.

\section{[Table 4 about here]}

Despite our attempts to control for various observable factors, our estimates could still be biased by unobservable factors correlated with both child sleep and mother's labour market outcomes. We try to assess the extent to which unobservables bias our estimates following the strategy proposed by Oster (2017). In Panel F, we consider two sets of regressions. Our

\footnotetext{
${ }^{36}$ Note that the ALSPAC data do not provide information on whether the father wakes up at night to deal with child sleeping problems. From Table 2, we know, however, that fathers are less affected by child sleeping problems.

${ }^{37}$ Choices of childcare uses, parenting style, mother ability to improve child sleeping routines are obviously endogenous to mother's labour supply. Ideally, we would like to instrument for these additional controls.

${ }^{38}$ Child cognitive performance is measured using math test scores. Child emotional health and behaviours are measured using the Strength and Difficulties Questionnaire.
} 
restricted regressions are unconditional regressions of mother sleep on economic performance and our full regressions are those in Panel F of Table $4 .{ }^{39}$ None of the ratios associated with the probability to work, the number of hours worked, and the log of income, reported in Table 4 , are less than 1. Their value ranges from 4.04 to 9.91 , with an average of 6.02 . This means that selection on unobservables would have to be at least 4 times that on observables and, on average, over roughly 6 times as strong to account for the full effects of sleep. These are large values, above the critical value of 1 . The probability to work and mother job satisfaction are binary outcomes. Therefore, we can also check the degree of selection on unobservables for these two variables using the methodology described by Altonji et al. (2015) for non-linear models. Similarly, we find that selection on unobservables would have to be at least 5 times that on observables, and 9 times as stronger to account for the full effects of sleep on mother employment, which is unlikely (see Panel F of Table 4).

We also conduct two alternative exercises to test for unobserved heterogeneity. First, Panel $\mathrm{G}$ of Table 4 run the 2SLS regressions by first-differencing mother labour market outcomes and mother sleep duration. The coefficients retain statistical significance. Panel $\mathrm{H}$ displays the reduced-form effects of mother labour market outcomes on child sleep duration and the number of times the child wakes up at night. In most cases, the relationships are statistically significant at the $1 \%$ level. They demonstrate economically important effects of child sleep on maternal labour market outcomes without requiring any exclusion restriction. Panel I replicates the analysis restricting the sample to families with children above 2 and below 5. Arguably, we would like to focus on the years right after paid maternity leave. Moreover, restricting the sample to children below 5 makes it more likely that factors driving children sleep patterns are exogenous. Our estimates slightly increase but remain qualitatively the same.

One might still argue that changes in within-child sleep are associated with some unobserved factors that could also influence mother labour market outcomes. One can try to assess the importance of the exclusion restriction for our results, using a method described in Conley et al. (2012). Applying their methodology to our case, we find that all the confidence intervals include our point estimates even with a substantial relaxation of the exclusion restriction (see Appendix Table A10). ${ }^{40}$ Assuming these estimations are compelling, this would

\footnotetext{
${ }^{39}$ Note that we follow Oster's suggestion and measure $R_{\max }^{2}$ as 1.3 times the R-squared of our full regressions in Panel F of Table 4.

${ }^{40}$ Conley et al. (2012) provide a method in which the correlation $\gamma$ between the instruments (child sleep duration and child sleep interruption) and the unobservables influencing mothers' labour market outcomes is assumed to
} 
imply that our results remain informative even if the exclusion restriction underlying the validity of our IV strategy is partially violated.

Another important threat to the identification lies in the reverse causality of mother's employment patterns on sleep and child outcomes. For instance, if the mother is struggling at work and brings stress back to the household, it is possible that her stress affects both her sleep patterns and the sleep patterns of her child. Similarly, mothers who want to work need that their child sleep better, and hence will exert more effort on training their child to sleep. To test for this simultaneity bias, Panel I presents the instrumental regressions using one-year lag for mother and child sleep duration - hence guaranteeing that mother labour supply at time $t$ could not possibly affect child sleep at time $\mathrm{t}-1$. This leads to a slight decrease in magnitudes but the coefficients remain statistically significant.

Still, one might argue that if there is persistence in mother economic conditions which in return affect her sleep patterns and child sleep patterns, using lags does not fully address these reverse causality concerns. Let us consider three arguments. First, Table 4 (Panels A-F) controls for parenting style, child-care arrangements, mother attitudes towards work and other variables which could be correlated with mother employment outcomes and sleep. Again, the results have been found to be remarkably robust to the inclusion of such controls. Second, if there is persistence in mother economic conditions, this should be partially controlled for after including mother-child fixed-effects and mother-child specific trends. Third, if mothers who work, need their child to sleep better, one should expect a significant effect of mother's labour force participation on child sleep patterns. However, Appendix Table A11 provides evidence that child sleep duration measured at different timepoints is not significantly longer when mother works. Similarly, the number of times a child wakes up at night is not consistently correlated with the mother's labour force participation, at least when the child is aged between 2 and 5, i.e. at the spike of the distribution.

As additional robustness checks, one can perform Granger causality tests to evaluate to which extent child sleep patterns cause mother labour market outcomes or vice versa. The results are reported in Table 4, Panels $\mathrm{Ka}$ and $\mathrm{Kb}$. The basic idea is that if past values of child sleep patterns (and mother sleep patterns) are significant predictors of the current value of mother labour market outcomes even when past values of mother labour market outcomes have

be near 0 but not exactly 0 . They first present different inference strategies where it is possible to specify a set of values for $\gamma$. Interval estimates for the coefficients of interest can then be obtained according to these different values. 
been included in the model, then child sleep patterns (and mother sleep patterns) exert a causal inference on labour market outcomes. According to Panel Ka, the coefficients of interest are all significant at the 5\% level, indicating that Granger causality from sleep patterns to mother labour market outcomes exists. Vice versa, in Panel $\mathrm{Kb}$, the coefficients on past values of mother's labour force participation and working hours are not significant. Note however that the coefficient on past value of income is positive and statistically significant at the $1 \%$ level. This is an indication that the relationship between sleep and wages is causal in both directions (according to Granger causality). ${ }^{41}$

Finally, our results are also robust to alternative specifications. In Appendix Table A12, we estimate our baseline results with child sleep duration used as a control, rather than an instrument. Arguably, child sleep disturbance is more plausibly independent of the second-stage error term than child sleep duration. Our estimates of mother sleep on mother economic performance increases but remain statistically significant. In Appendix Table A13, we replicate the baseline results, using probit instrumental regressions. The results remain statistically significant. In Appendix Table A14, we replicate our baseline estimates with standard errors clustered at the mother-child X year level (two-way clustering). This gives us robust results. We also perform a falsification test to assess the probability that reporting bias would drive our results. More specifically, we substitute mother sleep by another reported variable that is "satisfaction with neighbourhood". Appendix Table A15 reports the results. The coefficients are not statistically significant (except for household income). Finally, Appendix Table A16 presents our results excluding extreme values for mother sleep duration (i.e., mother reporting less than 2 hours of sleep on average per night). Similar results are obtained.

\section{Labour Market Careers and Flexible Time Schedules}

Previous sections conclude that mothers are less likely to work, work fewer hours and earn less when they have children with sleeping problems and these results are robust to various robustness checks. If such negative effects exist, one might expect the difference in the labour market outcomes among mothers to persist over time. In this last section, we document the impact of child-related sleep deprivation on mother labour market careers in the long run and discuss potential mechanisms. We then focus on the role of flexible time schedules.

\footnotetext{
${ }^{41}$ We provide further evidence on this issue using a distributed lag model in Section VII.
} 
Labour Market Careers. To assess the long-term impact of sleep deprivation, we first exploit the longitudinal dimension of the ALSPAC data. The mothers are observed up to 20 years after pregnancy. We run the baseline specifications where mother labour market outcomes are observed 5 years after measuring child sleep quality. Table 5 presents the results. On average, a one-hour reduction in sleep duration decreases the probability to work in 5 years by 3.1 percentage points $(\mathrm{s} . \mathrm{e}=0.018) .{ }^{42}$ This is smaller than the estimated magnitudes reported in Table 3, yet significant, suggesting that the effects are persistent over time. Column (2) presents the results on the number of working hours. The effect is 0.090 (s.e. $=0.054$ ). Again, given that they are measured five years later, the point estimates for sleep effects reflect some attenuation but remain persistent (this is 0.140 in Table 3 ). The difference in household income five years later from an increase in sleep duration by one hour per night is about 3.8\%. These are meaningful effects. The coefficient is not statistically significant for job satisfaction.

One might be worried that regressions with a single arbitrarily chosen lag will yield biased estimates. Appendix Table A17 provides results using a distributed lag model where lags from one to five years prior are included. The results indicate some interesting patterns. While the effects of sleep on mother labour force participation and hours worked quickly adjust, the effects on household income decrease at a lower rate and seem to be more persistent over time. This would suggest large cumulative effects of sleep deprivation on household income over five years.

How to understand the persistence of these effects? The presence of new children in the household do not account for this (see Appendix Table A17) nor do current health problems (see Appendix Table A18). By contrast, labour market mechanisms might put working mothers suffering from child-related sleep deprivation at a disadvantage. First, because mothers experiencing child-related sleep deprivation are exhausted, their effort and their productivity on the job might fall. Second, there might be wage costs associated with mother's work interruptions (due to child-related sleep deprivation) as they prevent mothers from the accumulation of additional human capital. Third, mothers' adaptation to their role of caregiver and the need to deal with child sleeping problems might influence their behaviours on the labour market - switching to part-time jobs or more mother-friendly employment, for example.

\section{[Table 5 about here]}

\footnotetext{
42 The results are robust to the use of alternative lags (e.g. 7 and 10 years later).
} 
Potential Mechanisms. To better understand the channels through which child-related sleep deprivation affects working mothers, we briefly examine its effects on alternative labour market outcomes. The first potential explanation advanced for a decrease in income is that mothers experience a fall in productivity. To test this, we look at the effect of sleep deprivation on the mother's probability to experience problems at work. Self-reported problems at work are not necessarily a high-quality measure of productivity at work. Yet, we believe that this provides a first indication of whether mothers suffering from child-related sleep deprivation encounter more difficulties at work. Table 5, Panel B, reports the results. The estimated coefficient reveals that a one-hour increase in average night sleep decreases the probability to experience problems at work by 9 percentage points.

The second explanation invoked was that mothers who experience child-related sleep deprivation might move from full-time to part-time jobs to provide them with the flexibility to manage their work and their family life. In other words, it is likely that child-related sleep deprivation affects incomes through conflicting schedules. In the ALSPAC data, mothers are asked whether they work in a full-time or a part-time job. Table 5 indicates that a one-hour reduction in sleep duration reduces the probability to work full-time by 3.8 percentage points. These are meaningful effects and suggest that selection into jobs matter. This is line with our previous results showing a significant effect on the number of working hours. Arguably, moving from full-time to part-time jobs is also likely to produce sustainable shocks on mothers' labour market careers and limit the convergence in the following years. ${ }^{43}$

If mothers decide to work part-time to deal with their family life, while their job satisfaction is not affected, this might reveal a change in values with respect to work, which could also explain the decrease in income and labour force participation. In the ALSPAC data, mothers are asked whether they have chosen to stay at home instead of work in the past year. In our sample, $16 \%$ of mothers did this choice. Work values can differ significantly across mothers. In our data, $49 \%$ declare working for financial reasons, $45 \%$ for their career, $16 \%$ for enjoyment and $30 \%$ for getting out of home. If mothers who have children with sleeping problems are also mothers who are less career-oriented, they may be more likely to quit their job and decide to stay at home to take care of their child. Moreover, if these mothers have no choice but to deal

\footnotetext{
43 These results are consistent with the view that part of the decrease in income is due to fewer hours of work and a shift towards more mother-friendly employment. This is also consistent with previous studies arguing that scheduling poses real problems for working mothers. In a 1997 Pew Research Center survey, 73\% of the 457 mothers interviewed rated a flexible work schedule as "very important" in choosing a job.
} 
with their child sleeping problems, this can increase their probability to subordinate their careers to the needs of their children, leading them to accept jobs for which they are over-qualified and with lower wages. Column (3) of Table 5 report the results. The estimates reveal a well-defined zero effect on the probability that mothers decide to stay at home instead of work due to childrelated sleep deprivation. Finally, we investigate the effects of child-related sleep deprivation on mother work-life balance. The ALSPAC data provides information on whether the mothers find it hard to cope with child after work. We replicate the baseline regressions with this variable as alternative outcome. Interestingly, one-hour reduction in sleep duration substantially increases the probability that mother finds hard to cope with child after work. ${ }^{44}$

Overall, these results are important - they provide a first attempt to explore potential mechanisms - but they are somewhat hindered by limited data. For instance, if women in the sample are financially constrained and hence feel compelled to work, the value of work could change substantially but they still would not choose to stay at home. Therefore, they have to be taken with caution. Further analysis would be required to convincingly isolate those channels.

Heterogeneous Effects. In Appendix Table A19, we also study heterogeneous effects with respect to: (i) child age (ii) whether the child is the first one or not, (iii) mother educational level, (iv) whether mother is self-employed, and (v) whether mother has organisation skills. There is some evidence of significant differences across these different subgroups. In particular, we see that the effects are concentrated among mothers with more than one child, stronger for mothers with no A level, and not "organised". This could suggest that some women have greater ability to adapt to poor child sleep.

Policy Implications. One policy implication of these results could be to provide more access to flexible time schedules. This could decrease the probability of mothers to opt out of the labour market or decrease their number of working hours when exposed to difficulties in dealing with family and work constraints. This last subsection investigates this type of policy and analyses the effect of the UK Employment Rights Act 1996, which provided the ability to parents who have worked more than 26 weeks to request flexibility working.

This policy change created a natural experiment that allow us to uniquely assess how flexible working can mediate the relationship between child-related sleep deprivation and

\footnotetext{
44 These results are again consistent with the idea that sleep deprivation influences mother work-life balance. Moreover, by reducing attention when coping with their child after work, sleep deprivation can also affect maternal coordination capacity. Consequently, this might have additional effects on the child development - reducing the amount of time the mother spent with the child - playing, reading, or doing other activities.
} 
mother labour market outcomes. Before the reform, mothers needed to work a standard core time and could not vary their start, finish and break times to adjust to child bearing. Similarly, there was no disposition to allow mothers to work from home or adjust their working hours. Such tight schedule was difficult and did not allow to combine family and work constraints. The UK Employment Rights Act 1996 applied the right to request flexible working to mothers with 26 weeks continuous employment, thus providing much broader possibilities to mothers to deal with family-life constraints, such as child sleep problems (e.g. working part-time, from home or compressed hours). ${ }^{45}$ Hence, we expect the negative effects of child-related sleep deprivation on mother labour market outcomes to be attenuated for mothers who had the right to request flexible working.

Fortunately, the ALSPAC data collects information on mothers' employment spell in 1996. We compute a dummy variable for whether the mothers were eligible to request flexible working in 1996 when the reform was implemented, and we analyse subsequent mother labour market outcomes. Though limited, this evidence is to our knowledge, new to the literature and fills a gap by documenting how public policies can tackle sleep-deprivation effects. Table 6 reports the triple difference estimates. The equation is as follows:

$$
\begin{aligned}
& \text { (3) } \mathrm{Y}_{\mathrm{it}}=\alpha+\beta \mathrm{MS}_{\mathrm{it}}+\theta \text { Post }_{\mathrm{t}}+\delta \text { Eligible }_{\mathrm{i}} \mathrm{MS}_{\mathrm{it}}+\zeta \text { Eligible }_{\mathrm{i}} \text { Post }_{\mathrm{t}}+\lambda \mathrm{MS}_{\mathrm{it}} \text { Post }_{\mathrm{t}} \\
& +v \mathrm{MS}_{\mathrm{it}} \text { Eligible }_{\mathrm{i}} \text { Post }_{\mathrm{t}}+\mathrm{X}_{\mathrm{it}} \gamma+\mu_{\mathrm{i}}+\varepsilon_{\mathrm{it}}
\end{aligned}
$$

where $v$ is our coefficient of interest and corresponds to the differential effect of mother sleep duration $\left(\mathrm{MS}_{\mathrm{it}}\right)$ for women who had the right to request flexible working (Eligible $\left.{ }_{\mathrm{i}}\right)$ after implementation of the UK Employment Rights Act 1996 (Post $t_{t}$. The results in Table 6 show that for mothers who were eligible to flexible working, the UK Employment Rights Act 1996 attenuated the effect of sleep duration on labour market performance. For eligible mothers, the marginal effect of sleep on labour force participation was $-0.021+0.102=0.081$ in the pre-reform period against $-0.021+0.102+0.013-0.071=0.023$ in the post-reform period. Not only, the probability to drop out of the labour force is lower by 7 percentage points, but also the decrease in the number of hours worked by $13 \%$. The marginal effect of sleep on the number of hours

\footnotetext{
45 Under UK employment rules, the statutory right to request flexible working entitles qualifying employees to apply to their employers for a change to their terms and conditions of employment relating to their hours, times or location of work. Employers may only refuse the request on grounds defined in legislation, for example, the burden of additional costs or a detrimental effect on the ability to meet customer demand.
} 
worked was $-0.036+0.207=0.171$ in the pre-reform period and $-0.036+0.207+0.013-$ $0.129=0.055$ in the post-reform period. In column (3), we report the results for household income. Here, the magnitude suggests again an attenuation of the relationship between sleep duration and household income by $1.3 \%$. Note that household income is a function of both mother and father sleep. It is unlikely that there both request flexible working. Hence, the effect could still be there at the household level. This first piece of evidence has the virtue of showing significant effect of public policies on sleep deprivation effects. Note, however, that these effects could potentially suffer from endogeneity bias, as mother characteristics could affect both the probability to be eligible and the probability to request flexible working. However, given that workers in the sample chose jobs well before the reform was enacted, this is less of a concern. To be on the safe side, we include a robustness check, in Appendix Table A20, where we perform placebo tests investigating the effects of the reform 3, 2, and 1 year prior. Reassuringly, we find no effect for the interaction terms between maternal sleep duration and the right to request flexible working 3,2 and 1 year prior the implementation of the reform (except for household income). ${ }^{46}$ As an additional robustness check, we substitute mother sleep with father sleep in our main specifications. Again, we find no significant effect for the interaction terms between father sleep duration and the reform on mother labour market outcomes (Appendix Table A21). ${ }^{47}$

\section{[Table 6 about here]}

\section{Conclusion}

This paper shows that child sleep patterns exert a significant effect on maternal sleep quality and mother labour market outcomes, both in the short run and in the long run. Using child sleep as a source of variation during child-bearing time, mother sleep duration significantly influences mother labour force participation, alongside the number of hours worked and the resulting household income. Flexible time schedules mitigate the negative effects, while fathers are somewhat less affected by child sleep problems. Although we cannot fully rule out the

\footnotetext{
46 This might suggest that households for whom the sleep-income relationship was stronger were more likely to be eligible and request flexible working schedules.

47 To avoid taking into account the positive correlation between mother sleep duration and father sleep duration which could bias our results, we first residualise father sleep duration controlling for mother sleep duration and the usual set of covariates.
} 
existence of endogeneity issues, we believe that this paper provides the first estimates of the effect of child-related sleep deprivation on parental economic activity.

Many economists and social scientists have studied how people allocate time to competing activities, and most prominently income and leisure. However, they have largely ignored the time spent sleeping and its impact on economic activity. The substantial effects of child sleep patterns on mother sleep, and labour market choices suggest that by ignoring this area, the vast literature on labour supply contains a difficulty that could have important consequences for understanding the allocation of time between home and the market. These effects are particularly important in a context of slow-moving social norms and persistent traditional roles within households. We conclude that sleep should be a significant variable to consider in the design of employment policies to supporting working mothers.

While our empirical work focuses on the United Kingdom, strong and persistent negative effects of motherhood on women labour force participation and income are found in a large number of countries. Several policies have been enacted over the past decades across the industrial world to help mothers dealing with family and career choices. Key among those are maternity and parental leave systems. Others include access to more flexible working schedules. Additional research would be required to understand how such policies can help working mothers in the context of sleep deprivation.

In future work, we would like to understand better how sleep deprivation affects individual choices and behaviours in a broad range of situations. While the evidence in this article suggests that child-related sleep deprivation helps explain parental economic outcomes, this could also affect the patterns of divorce, social relationships and health of parents. More research on these areas should be encouraged. 


\section{References}

Acebo C., Sadeh, A., Seifer, R., Tzischinsky, O. Hafer A., and Carskadon M.A. (2005) Sleep/wake patterns derived from activity monitoring and maternal report for healthy 1 to 5year old children. Sleep, 28(12), 1568-1577.

Altonji, J.G, Elder, T.E., and Taber, C.R. (2005). Selection on observed and unobserved variables: Assessing the effectiveness of catholic schools. Journal of Political Economy, 113(1), 151-184.

Anderson, D.J., Binder, M. and Krause, K. (2003). The motherhood wage penalty revisited: Experience, heterogeneity, work effort, and work-schedule flexibility. Industrial and Labor Relations Review, 56(2), 273-294.

Antillón, M., D.S. Lauderdale, and Mullahy J. (2014). Sleep behaviour and unemployment conditions. Economics \& Human Biology, 14, 22-32.

Arber, S., Bote, M., and Meadows, R. (2009). Gender and socio-economic patterning of selfreported sleep problems in Britain. Social Science \& Medicine, 68(2), 281-289.

Ásgeirsdóttir, T. L., and Ólafsson, S. P. (2015). An empirical analysis of the demand for sleep: Evidence from the American time use survey. Economics \& Human Biology, 19, 265-274.

Bank, S., and Dinges, D.F. (2007). Behavioural and physiological consequences of sleep restriction. Journal of Clinical Sleep Medicine, 33(5), 519-528.

Barclay, N. L., Eley, T. C., Buysse, D. J., Rijsdijk, F. V., and Gregory, A. M. (2010). Genetic and environmental influences on different components of the Pittsburgh Sleep Quality Index and their overlap. Sleep, 33(5), 659.

Becker, G.S (1965). A theory of the allocation of time. Economic Journal, 75, 493-517.

Biddle, J and D. Hamermesh (1990) Sleep and the allocation of time. Journal of Political Economy, 98 (5), 922-943.

Blair, P.S., Humphreys, J.S., Gringras, P., Taheri, S., Scott, N., Emond, A., Henderson, J. and P. J. Fleming. (2012). Childhood sleep duration and associated demographic characteristics in an English cohort. Sleep, 35(3), 353-360.

Blau, F. and Kahn, L. (2006). The U.S. gender pay gap in the 1990s: Slowing convergence. Industrial and Labor Relations Review, 60(1), 45-66.

Blau, F. and Kahn, L. (2013). Female labor supply: Why is the United States falling behind? American Economic Review, 103(3), 251-56.

Bloom, D., Canning D., Günther F, and Jocelyn F, (2009). Fertility, female labour force participation, and the demographic dividend," Journal of Economic Growth, 14(2), 79-101.

Bonke, J. (2012). Do morning-type people earn more than evening-type people? How chronotypes influence income. Annals of Economics and Statistics, 105/106, 55-72.

Boyd, A., Golding, J., Macleod, J., Lawlor, D. A., Fraser, A., Henderson, J. and Smith, G. D. (2012). Cohort profile: the 'children of the 90s' - the index offspring of the Avon Longitudinal Study of Parents and Children. International Journal of Epidemiology, dys064.

Brochu, P., Armstrong, C. D., and Morin, L. P. (2012). The 'trendiness' of sleep: An empirical investigation into the cyclical nature of sleep time. Empirical Economics, 43(2), 891-913.

Conley, T.G., Hansen, C.B and Rossi, P.E. (2012). Plausibly exogenous. Review of Economics and Statistics, 94(1), 260-272.

Costa Dias, M., Elming, W. and Joyce, R. (2016). The gender wage gap. IFS Briefing Note BN186, The Institute for Fiscal Studies.

Dionne G., Touchette, E., and Forget-Dubois, N. (2011). Association between sleep-wake consolidation and language development in early childhood: A longitudinal twin study. Sleep, 34(8), 987-995.

DiPrete, T. and Buchmann, C. (2006). The growing female advantage in college completion: The role of family background and academic achievement, American Sociological Review, 
71(4), 515-541.

Frank M.G. (2006). The mystery of sleep function: current perspectives and future directions. Reviews in the Neurosciences. 17, 375-39.

Galland, B. C., Taylor, B. J., Elder, D. E., and Herbison, P. (2012). Normal sleep patterns in infants and children: A systematic review of observational studies. Sleep Medicine Reviews, 16(3), 213-222.

Gehrmann P.R., Meltzer I.J., and Moore M. (2011). Heritability of insomnia symptoms in youth and their relationship to depression and anxiety. Sleep. 34(12). 1641-1646.

Gibson, M., and Shrader, J., (2018). Time use and productivity: The wage returns to sleep. Review of Economics and Statistics, Early access.

Grandner, M. A., Patel, N. P., Gehrman, P. R., Xie, D., Sha, D., Weaver, T., and Gooneratne, N. (2010). Who gets the best sleep? Ethnic and socioeconomic factors related to sleep complaints. Sleep Medicine, 11(5), 470-478.

Grossman, M. (1972). The demand for health: A theoretical and empirical investigation. NBER Books.

Hamermesh, D.S., Frazis, H. and Steward, J. (2005). The American time-use survey. Journal of Economic Perspectives, 19(1), 221-232.

Hamermersh, D.S., Knowles Myres, C and Pocock, A.L. (2008). Cues for Timing and Coordination: Latitude, Letterman and Longitude. Journal of Labour Economics, 26 (2), 223-247.

Heckman, J.J. and MaCurdy, T.E. (1980). A life cycle model of female labour supply. Review of Economic Studies, 47, 47-74.

Iglowstein I, Jenni O.G., Molinari I., and Largho R.H. (2003). Sleep duration from infancy to adolescent: Reference values and generational trends. Paediatrics. 111(2), 302-307.

Kahn M., Fridenson S., Lerer R., Bar-Haim Y., and Sadeh A. (2014). Effects of one night of induced night-wakings versus sleep restriction on sustained attention and mood: A pilot study. Sleep Medicine, 15, 825-832.

Kamstra, M. J., Kramer, L. A., and Levi, M. D., (2000). Losing sleep at the market: The daylight-saving anomaly. American Economic Review, 90(4), 1005-1011.

Killgore, W., (2010). Effects of sleep deprivation on cognition. Human Sleep and Cognition: Basic Research, 185.

Mezick, E. J., Matthews, K. A., Hall, M., Strollo Jr, P. J., Buysse, D. J., Kamarck, T. W. and Reis, S. E. (2008). Influence of race and socioeconomic status on sleep: Pittsburgh Sleep SCORE project. Psychosomatic Medicine,70(4), 410.

Michael, R.T (1973). Education in nonmarket production. Journal of Political Economy, 81(2), pt.1, 306-27.

Mindell J. A., Sadeh A., Kwon R., and Goh D. Y (2013). Cross-cultural differences in the sleep of preschool children. Sleep Medicine, 14, 1283-1289.

Mindell, J. A., Sadeh, A., Kwon, R., and Goh, D. Y. (2015). Relationship between child and maternal sleep: A developmental and cross-cultural comparison. Journal of Pediatric Psychology, 40(7), 689-696.

Moore M., Slane J, Mindell J.A., Burt S.A. and Klump K.L. (2011). Genetic and environmental influences on sleep problems: A study of preadolescent and adolescent twins. Child Care Health Development. 37(5), 638-641.

Moore, P. J., Adler, N. E., Williams, D. R., and Jackson, J. S. (2002). Socioeconomic status and health: The role of sleep. Psychosomatic Medicine, 64(2), 337-344

Oster, E. (2017). Unobservable selection and coefficient stability: Theory and validation. Journal of Business Economics and Statistics, forthcoming.

Palmstierna, P., Sepa, A. and Ludvigsson, J. (2008). Parent perceptions of child sleep: A study of 10,000 Swedish children. Acta Paediatr, 97(12), 1631-1639. 
Pilcher, J. J., and Huffcutt, A. J. (1996). Effects of sleep deprivation on performance: A metaanalysis. Sleep: Journal of Sleep Research \& Sleep Medicine, 19(4), 318-26.

Schober, M.F. and Conrad, F.G. (1997). Does conversational interviewing reduce survey measurement error? Public Opinion Quarterly, 61, 576-602.

Siegel J.M. (2005.) Clues to the functions of mammalian sleep. Nature. 437, 1264-1271.

Szalontai, G. (2006). The demand for sleep: A South African study. Economic Modelling, 23(5), 854-874.

Tafti M., Maret S., and Dauvilliers, Y. (2005). Genes for normal sleep and sleep disorders. Ann Med, 37(8), 580-589.

Touchette, E., Dionne, G., Forget-Dubois N., Petit D., Pérusse, D., Falissard B., Tremblay R.E., Boivin M., and Montplaisir J.Y., (2013). Genetic and environmental influences on daytime and nighttime sleep duration in early childhood. Pediatrics, 131(6), 1874-1880.

Van Dongen, H.P.A., and Dinges, D.F. (2005). Sleep, circadian rhythms, and psychomotor vigilance. Clinics in Sports Medicine, 24(2), 237-249.

Waldfogel, J. (1995). The price of motherhood: Family status and women's pay in a young British cohort. Oxford Economic Papers, 47(4), 584-610.

Waldfogel, J. (1997). The effect of children on women's wages. American Sociological Review, $62(2), 209-217$.

Waldfogel, J. (1998). Understanding the family gap in pay for women with children. Journal of Economic Perspectives, 12(1), 137-56.

Weichselbaumer, D., and Winter-Ebmer, R. (2005). A meta-analysis of the international gender wage gap. Journal of Economic Surveys, 19(3), 479-511. 
Figure 1: The Number of Times a Child Wakes up At Night by Age

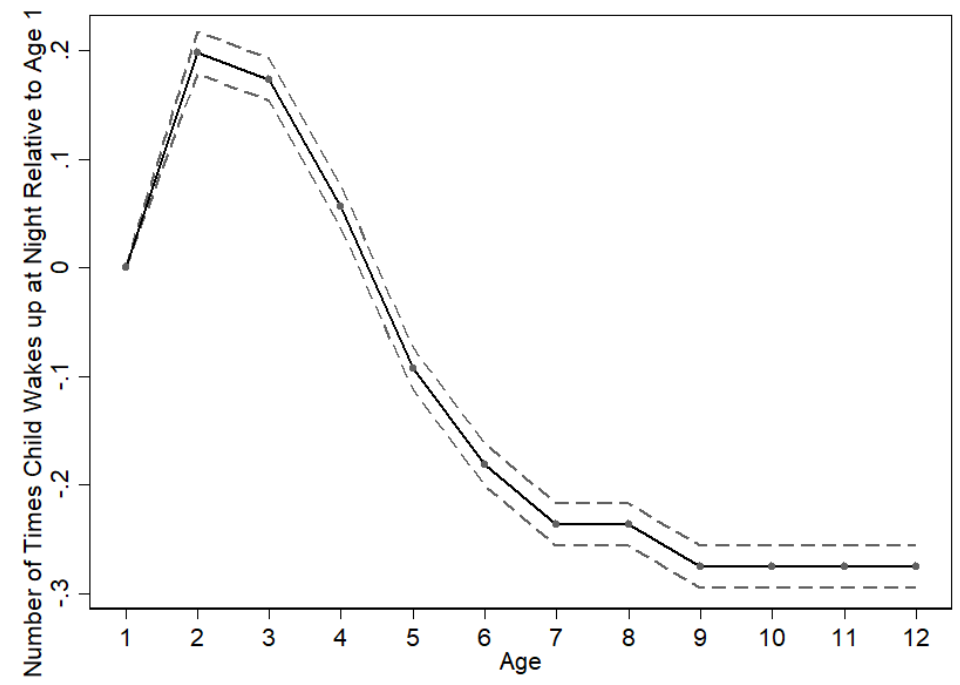

Notes: The figure represents the differences in the number of times a child wakes up at night per night relative to the first year of life by child age.

Figure 2: The Relationship between the Number of Times the Child Wakes up at Night and Mother Sleep Duration

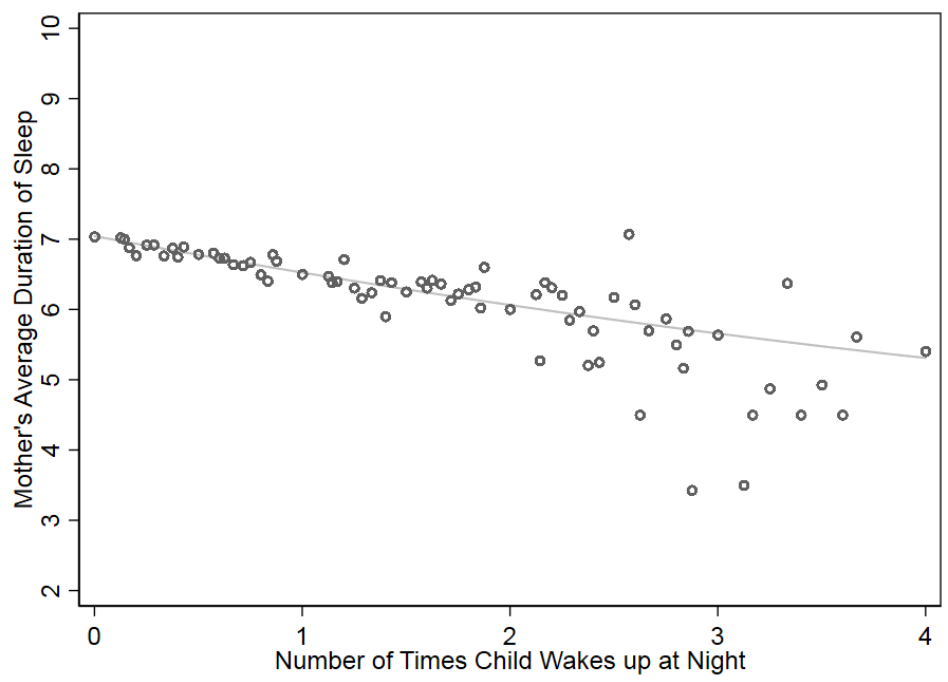

Notes: The figure is a scatter plot of mother's average duration of sleep against the number of times the child wakes up at night. To construct this scatter plot, we first average the number of times the child wakes up at night by mother-child pairs. We then plot the means of the y-variable within each average against the mean value of the number of times the child wakes up at night within each mother-child pair. The solid line shows the best quadratic fit estimated. 
Table 1. Descriptive Statistics of Families with Child under 12

\begin{tabular}{rccccc}
\hline \hline & $(1)$ & $(2)$ & $(3)$ & $(4)$ & $(5)$ \\
& Obs. & Mean & Sd & Min & Max \\
\cline { 2 - 6 } Sleep related variables: & & & & \\
Child duration of sleep: hours & 142,081 & 11.13 & $(1.24)$ & 1 & 18 \\
Child wakes up at night: Yes/No & 142,081 & 0.29 & $(0.45)$ & 0 & 1 \\
Frequency child wakes up at night & 142,081 & 0.42 & $(0.78)$ & 0 & 4 \\
Child has a regular sleeping routine & 142,052 & 0.92 & $(0.27)$ & 0 & 1 \\
Mother duration of sleep: hours & 142,081 & 6.86 & $(1.38)$ & 0 & 9 \\
Mother sleeps less than 6 hours & 142,081 & 0.13 & $(0.34)$ & 0 & 1 \\
Mother sleeps between 6 and 7 hours & 142,081 & 0.54 & $(0.50)$ & 0 & 1 \\
Mother is getting enough sleep & 141,125 & 0.59 & $(0.49)$ & 0 & 1 \\
Father duration of sleep: hours & 99,888 & 6.74 & $(1.36)$ & 0 & 9 \\
Father is getting enough sleep & 100,022 & 0.62 & $(0.49)$ & 0 & 1 \\
& & & & & \\
& & & & & \\
Mother works & 142,081 & 0.59 & $(0.49)$ & 0 & 1 \\
Father works & 121,966 & 0.84 & $(0.36)$ & 0 & 1 \\
Mother works part-time & 135,276 & 0.23 & $(0.42)$ & 0 & 1 \\
Employment related variables: & 133,297 & 21.58 & $(11.79)$ & 1 & 90 \\
Mothers hours worked per week & 132,595 & 23,229 & $(13,691)$ & 2,934 & 72,131 \\
Household income (2008 prices) & 121,595 & $(0.48)$ & 0 & 1 \\
Mother is satisfied with job & 78,061 & 0.66 &
\end{tabular}

Notes: This table provides the list, arithmetic mean and standard deviation alongside extreme values of all sleep and labour variables of interest. 
Table 2: Effect of Child Sleep Duration and Child Sleep Disruption on Parental Sleep Quality (First Stage)

\begin{tabular}{|c|c|c|c|c|c|c|}
\hline & $\begin{array}{c}\text { Mother's sleep } \\
\text { duration } \\
(1) \\
\end{array}$ & $\begin{array}{l}\text { Mother sleeps } \\
\text { less than } 6 \\
\text { hours } \\
\text { (2) } \\
\end{array}$ & $\begin{array}{c}\text { Mother has } \\
\text { enough sleep } \\
\text { (3) } \\
\end{array}$ & $\begin{array}{c}\Delta \text { (Mother's } \\
\text { sleep duration) } \\
(4) \\
\end{array}$ & $\begin{array}{c}\text { Mother's sleep } \\
\text { duration } \\
\text { (3 years lagged) } \\
(5) \\
\end{array}$ & $\begin{array}{c}\begin{array}{c}\text { Father's sleep } \\
\text { duration }\end{array} \\
(6) \\
\end{array}$ \\
\hline $\begin{array}{l}\text { No. of times child } \\
\text { wakes up at night }\end{array}$ & $\begin{array}{l}-0.105 \\
(0.007)\end{array}$ & $\begin{array}{c}0.023 \\
(0.002)\end{array}$ & $\begin{array}{l}-0.036 \\
(0.002)\end{array}$ & & $\begin{array}{c}-0.014 \\
(0.012)\end{array}$ & $\begin{array}{l}-0.044 \\
(0.007)\end{array}$ \\
\hline Child's sleep duration & $\begin{array}{c}0.028 \\
(0.005)\end{array}$ & $\begin{array}{l}-0.009 \\
(0.001)\end{array}$ & $\begin{array}{c}0.007 \\
(0.002)\end{array}$ & & $\begin{array}{l}-0.012 \\
(0.007)\end{array}$ & $\begin{array}{c}0.009 \\
(0.004)\end{array}$ \\
\hline $\begin{array}{l}\Delta \text { (No. of times child } \\
\text { wakes up at night) }\end{array}$ & & & & $\begin{array}{l}-0.036 \\
(0.006)\end{array}$ & & \\
\hline $\begin{array}{l}\Delta \text { (Child's sleep } \\
\text { duration) }\end{array}$ & & & & $\begin{array}{c}0.099 \\
(0.004)\end{array}$ & & \\
\hline Observations & 142,081 & 142,081 & 141,125 & 130,192 & 106,599 & 99,888 \\
\hline R-squared & 0.644 & 0.587 & 0.624 & 0.0497 & 0.642 & 0.742 \\
\hline Child controls & Yes & Yes & Yes & Yes & Yes & Yes \\
\hline Parent controls & Yes & Yes & Yes & Yes & Yes & Yes \\
\hline Mother-child FE & Yes & Yes & Yes & Yes & Yes & Yes \\
\hline No. of mother-child & 11,935 & 11,935 & 11,857 & 11,935 & 11,935 & 8,501 \\
\hline
\end{tabular}

Notes: All specifications are estimated using OLS and include mother-child fixed effects. Specifications (1) to (5) also control for child's age dummies, child health, mother's general health, mother's mental health, the number of children in the household, whether mother is separated, and environmental triggers (noise and whether child shares bedroom). Specification (6) controls for the same child covariates but includes father's general health, father's mental health, the number of children in the household, and the same environmental triggers (noise and whether child shares bedroom). Clustered standard errors on mother-child are in parentheses. 
Table 3: Effect of mother sleep duration on mother's economic performance

\begin{tabular}{lcccc}
\hline \hline & $\begin{array}{c}\text { Probability to } \\
\text { work } \\
(1)\end{array}$ & $\begin{array}{c}\text { Log } \\
\text { (Hours worked }) \\
(2)\end{array}$ & $\begin{array}{c}\text { Log } \\
\text { (HH income) } \\
(3)\end{array}$ & $\begin{array}{c}\text { Satisfied } \\
\text { with job } \\
(4)\end{array}$ \\
\hline Panel A: Correlation (OLS) & 0.010 & 0.028 & 0.016 & -0.004 \\
Sleep (hours) & $(0.002)$ & $(0.005)$ & $(0.002)$ & $(0.003)$ \\
& & & & \\
Panel B: Instrumental variables (2SLS) & 0.050 & 0.140 & 0.099 & 0.003 \\
Sleep (hours) & $(0.021)$ & $(0.060)$ & $(0.018)$ & $(0.035)$ \\
& 142,081 & 133,297 & 121,595 & 78,061 \\
Observations & 11,935 & 11,832 & 10,610 & 9,325 \\
No. of mothers & 0.591 & 1.631 & 5.754 & 0.660 \\
Outcome mean & 0.491 & 1.511 & 0.685 & 0.479 \\
Outcome standard deviation & 126.5 & 118 & 139.8 & 45.98 \\
Kleibergen-Paap statistic & & & \\
\hline
\end{tabular}

Notes: Specifications in Panel A are estimated using OLS, and include mother-child fixed effects, child's age dummies, child health, mother's general health, mother's mental health, the number of children in the household, whether mother is separated, and environmental triggers (noise and whether child shares the bedroom). Specifications in column 3 also include father's sleep duration. Specifications in Panel B include the same covariates but are estimated using 2SLS. The number of observations across outcomes varies due to data availability. Clustered standard errors on mother-child are in parentheses. 
Table 4: Robustness Checks

\begin{tabular}{|c|c|c|c|c|}
\hline & $\begin{array}{l}\text { Probability } \\
\text { to work } \\
\text { (1) }\end{array}$ & $\begin{array}{l}\text { Log (Hours } \\
\text { worked) } \\
\text { (2) }\end{array}$ & $\begin{array}{c}\log (\mathrm{HH} \\
\text { income) } \\
(3)\end{array}$ & $\begin{array}{l}\text { Satisfied } \\
\text { with job } \\
\text { (4) }\end{array}$ \\
\hline \multicolumn{5}{|l|}{ Panel A: Controlling for life events (2SLS) } \\
\hline Sleep (hours) & $\begin{array}{c}0.041 \\
(0.021)\end{array}$ & $\begin{array}{c}0.119 \\
(0.060)\end{array}$ & $\begin{array}{c}0.094 \\
(0.019)\end{array}$ & $\begin{array}{c}0.004 \\
(0.034)\end{array}$ \\
\hline Observations & 142,081 & 133,297 & 121,595 & 78,061 \\
\hline \multicolumn{5}{|c|}{ Panel B: Controlling for household composition (2SLS) } \\
\hline Sleep (hours) & $\begin{array}{c}0.043 \\
(0.021)\end{array}$ & $\begin{array}{c}0.120 \\
(0.060)\end{array}$ & $\begin{array}{c}0.106 \\
(0.020)\end{array}$ & $\begin{array}{c}0.003 \\
(0.035)\end{array}$ \\
\hline Observations & 142,081 & 133,297 & 121,595 & 78,061 \\
\hline \multicolumn{5}{|c|}{ Panel C: Controlling for father characteristics (2SLS) } \\
\hline Sleep (hours) & $\begin{array}{c}0.051 \\
(0.021)\end{array}$ & $\begin{array}{c}0.143 \\
(0.062)\end{array}$ & $\begin{array}{c}0.154 \\
(0.019)\end{array}$ & $\begin{array}{c}0.005 \\
(0.036)\end{array}$ \\
\hline Observations & 142,081 & 133,297 & 121,595 & 78,061 \\
\hline \multicolumn{5}{|c|}{ Panel D: Controlling for mother attitudes towards work and parenting style (2SLS) } \\
\hline Sleep (hours) & $\begin{array}{c}0.079 \\
(0.021)\end{array}$ & $\begin{array}{c}0.251 \\
(0.061)\end{array}$ & $\begin{array}{c}0.176 \\
(0.019)\end{array}$ & $\begin{array}{l}-0.004 \\
(0.036)\end{array}$ \\
\hline Observations & 142,081 & 133,297 & 121,595 & 78,061 \\
\hline \multicolumn{5}{|c|}{ Panel E: Controlling for child emotional health and behaviours (2SLS) } \\
\hline Sleep (hours) & $\begin{array}{c}0.045 \\
(0.021)\end{array}$ & $\begin{array}{c}0.120 \\
(0.060)\end{array}$ & $\begin{array}{c}0.066 \\
(0.018)\end{array}$ & $\begin{array}{c}0.004 \\
(0.035)\end{array}$ \\
\hline Observations & 142,081 & 133,297 & 121,595 & 78,061 \\
\hline \multicolumn{5}{|l|}{ Panel F: All controls (2SLS) } \\
\hline Sleep (hours) & $\begin{array}{c}0.058 \\
(0.021) \\
142.081\end{array}$ & $\begin{array}{c}0.184 \\
(0.062) \\
133.297\end{array}$ & $\begin{array}{c}0.057 \\
(0.020) \\
121.595\end{array}$ & $\begin{array}{l}-0.001 \\
(0.037) \\
78.061\end{array}$ \\
\hline$\hat{\delta}=\hat{\rho}\left(R_{F}^{2}-R_{R}^{2}\right) /\left(R_{\max }^{2}-R_{F}^{2}\right)$, Oster $(2017)$ & 9.911 & 4.039 & 4.127 & 0.238 \\
\hline$\Lambda$, Altonji et al. $(2015)$ & 11.496 & & & 4.076 \\
\hline \multicolumn{5}{|l|}{ Panel G: First difference estimates (2SLS) } \\
\hline$\Delta($ Sleep (hours) $)$ & $\begin{array}{c}0.101 \\
(0.013)\end{array}$ & $\begin{array}{c}0.346 \\
(0.035)\end{array}$ & $\begin{array}{c}0.028 \\
(0.013)\end{array}$ & $\begin{array}{c}0.191 \\
(0.024)\end{array}$ \\
\hline Observations & 130,192 & 122,014 & 111,593 & 74,043 \\
\hline \multicolumn{5}{|l|}{ Panel H: Reduced form } \\
\hline No. of times child wakes up at night & $\begin{array}{l}-0.013 \\
(0.002)\end{array}$ & $\begin{array}{l}-0.041 \\
(0.007)\end{array}$ & $\begin{array}{l}-0.030 \\
(0.002)\end{array}$ & $\begin{array}{c}0.000 \\
(0.003)\end{array}$ \\
\hline Child's sleep duration & $\begin{array}{l}-0.011 \\
(0.002)\end{array}$ & $\begin{array}{c}-0.042 \\
(0.005)\end{array}$ & $\begin{array}{c}-0.045 \\
(0.001)\end{array}$ & $\begin{array}{c}0.001 \\
(0.002)\end{array}$ \\
\hline Observations & 142,081 & 133,297 & 121,595 & 78,061 \\
\hline \multicolumn{5}{|c|}{ Panel I: Restricting the sample to children aged 2-5 } \\
\hline Sleep (hours) & $\begin{array}{c}0.123 \\
(0.052)\end{array}$ & $\begin{array}{c}0.287 \\
(0.118)\end{array}$ & $\begin{array}{c}0.052 \\
(0.036)\end{array}$ & $\begin{array}{l}-0.015 \\
(0.054)\end{array}$ \\
\hline Observations & 46,964 & 43,191 & 39,444 & 21,854 \\
\hline \multicolumn{5}{|l|}{ Panel J: Lagged estimates (2SLS) } \\
\hline Sleep (hours) - 1 year lagged & $\begin{array}{c}0.021 \\
(0.035)\end{array}$ & $\begin{array}{c}0.136 \\
(0.105)\end{array}$ & $\begin{array}{c}0.269 \\
(0.037)\end{array}$ & $\begin{array}{l}-0.020 \\
(0.058)\end{array}$ \\
\hline Observations & 130,192 & 122,014 & 111,593 & 74,043 \\
\hline \multicolumn{5}{|l|}{ Panel Ka: Granger causality tests } \\
\hline Sleep (hours) - 1 year lagged & $\begin{array}{c}0.003 \\
(0.001)\end{array}$ & $\begin{array}{c}0.008 \\
(0.003)\end{array}$ & $\begin{array}{c}0.005 \\
(0.001)\end{array}$ & $\begin{array}{l}-0.003 \\
(0.002)\end{array}$ \\
\hline Observations & 130,199 & 119,556 & 111,019 & 66,003 \\
\hline \multicolumn{5}{|l|}{ Panel Kb: Granger causality tests } \\
\hline Sleep (hours) - dependent variable & $\begin{array}{c}0.003 \\
(0.007)\end{array}$ & $\begin{array}{c}0.002 \\
(0.003)\end{array}$ & $\begin{array}{c}0.048 \\
(0.008)\end{array}$ & $\begin{array}{c}-0.023 \\
(0.009)\end{array}$ \\
\hline Observations & 130,199 & 121,876 & 111,019 & 70,167 \\
\hline
\end{tabular}

Notes: See Table 3 for reduced form and IV estimation. Robustness checks are described in detail in the text. 
Table 5: Effect of Mother Sleep in the Long Term and Other Labour Market Outcomes

\begin{tabular}{|c|c|c|c|c|}
\hline & $\begin{array}{l}\text { Probability to } \\
\text { work } \\
5 \text { years later } \\
\text { (1) } \\
\end{array}$ & $\begin{array}{l}\text { Log }(\text { Hours } \\
\text { worked) } \\
5 \text { years later } \\
(2)\end{array}$ & $\begin{array}{c}\begin{array}{c}\log (\mathrm{HH} \text { income }) \\
5 \text { years later } \\
(3)\end{array} \\
\end{array}$ & $\begin{array}{l}\text { Satisfied with job } \\
5 \text { years later } \\
\text { (4) }\end{array}$ \\
\hline $\begin{array}{l}\text { Panel A: Correlation (OLS) } \\
\text { Sleep (hours) }\end{array}$ & $\begin{array}{c}0.003 \\
(0.001)\end{array}$ & $\begin{array}{c}0.018 \\
(0.004)\end{array}$ & $\begin{array}{c}0.020 \\
(0.001)\end{array}$ & $\begin{array}{c}0.000 \\
(0.002)\end{array}$ \\
\hline $\begin{array}{l}\text { Panel B: Instrumental variables (2SLS) } \\
\text { Sleep (hours) }\end{array}$ & $\begin{array}{c}0.031 \\
(0.018)\end{array}$ & $\begin{array}{c}0.090 \\
(0.054)\end{array}$ & $\begin{array}{c}0.038 \\
(0.016)\end{array}$ & $\begin{array}{c}0.006 \\
(0.024)\end{array}$ \\
\hline $\begin{array}{l}\text { Observations } \\
\text { No. of mothers } \\
\text { Outcome mean } \\
\text { Outcome standard deviation } \\
\text { Kleibergen-Paap statistic }\end{array}$ & $\begin{array}{c}82,469 \\
11,874 \\
0.651 \\
0.476 \\
126.2\end{array}$ & $\begin{array}{c}78,038 \\
11,598 \\
1.841 \\
1.490 \\
113.2\end{array}$ & $\begin{array}{l}71,702 \\
10,559 \\
5.810 \\
0.690 \\
180.9\end{array}$ & $\begin{array}{l}51,532 \\
8,863 \\
0.635 \\
0.481 \\
87.71\end{array}$ \\
\hline & $\begin{array}{c}\text { Mother has } \\
\text { problems at work } \\
\text { (1) } \\
\end{array}$ & $\begin{array}{l}\text { Probability to } \\
\text { work full time } \\
\text { (2) }\end{array}$ & $\begin{array}{c}\text { Mother chooses to } \\
\text { stay at home } \\
\text { instead of work } \\
\text { (3) } \\
\end{array}$ & $\begin{array}{l}\text { Mother finds hard } \\
\text { to cope with child } \\
\text { after work } \\
\text { (4) } \\
\end{array}$ \\
\hline $\begin{array}{l}\text { Panel A: Correlation (OLS) } \\
\text { Sleep (hours) }\end{array}$ & $\begin{array}{l}-0.006 \\
(0.004)\end{array}$ & $\begin{array}{c}0.002 \\
(0.001)\end{array}$ & $\begin{array}{c}0.002 \\
(0.003)\end{array}$ & $\begin{array}{l}-0.023 \\
(0.006)\end{array}$ \\
\hline $\begin{array}{l}\text { Panel B: Instrumental variables (2SLS) } \\
\text { Sleep (hours) }\end{array}$ & $\begin{array}{l}-0.090 \\
(0.036)\end{array}$ & $\begin{array}{c}0.038 \\
(0.017)\end{array}$ & $\begin{array}{l}-0.001 \\
(0.024)\end{array}$ & $\begin{array}{l}-0.139 \\
(0.067)\end{array}$ \\
\hline $\begin{array}{l}\text { Observations } \\
\text { No. of mothers } \\
\text { Outcome mean } \\
\text { Outcome standard deviation } \\
\text { Kleibergen-Paap statistic }\end{array}$ & $\begin{array}{l}55,409 \\
11,864 \\
1.423 \\
0.922 \\
154.6 \\
\end{array}$ & $\begin{array}{c}135,276 \\
9,780 \\
0.770 \\
0.420 \\
199.1 \\
\end{array}$ & $\begin{array}{l}22,098 \\
8,424 \\
0.161 \\
0.368 \\
57.85\end{array}$ & $\begin{array}{c}14,096 \\
7,211 \\
1.868 \\
0.676 \\
27.16\end{array}$ \\
\hline
\end{tabular}

Notes: Specifications in Panels A are estimated using OLS, and include mother-child fixed effects, child's age dummies, child health, mother's general health, mother's mental health, the number of children in the household, whether mother is separated, and environmental triggers (noise and whether child shares the bedroom). Specifications in column 3 (log HH income) also include father's sleep duration. Specifications in Panels B include the same covariates but are estimated using 2SLS. The number of observations across outcomes varies due to data availability. Clustered standard errors on mother-child are in parentheses. 
Table 6: Effect of the Employment Rights Act 1996 on Mother Sleep and Economic Performance

\begin{tabular}{|c|c|c|c|c|}
\hline & $\begin{array}{l}\text { Probability to } \\
\text { work } \\
\text { (1) } \\
\end{array}$ & $\begin{array}{c}\text { Log } \\
\text { (Hours worked) } \\
(2) \\
\end{array}$ & $\begin{array}{c}\log \\
\text { (HH income) } \\
(3) \\
\end{array}$ & $\begin{array}{c}\text { Satisfied with job } \\
\text { (4) } \\
\end{array}$ \\
\hline \multicolumn{5}{|l|}{ Panel A: Correlation (OLS) } \\
\hline Sleep (hours) & $\begin{array}{c}0.010 \\
(0.002)\end{array}$ & $\begin{array}{c}0.020 \\
(0.006)\end{array}$ & $\begin{array}{c}0.005 \\
(0.001)\end{array}$ & $\begin{array}{c}-0.002 \\
(0.004)\end{array}$ \\
\hline \multicolumn{5}{|l|}{ Panel B: Triple differences (OLS) } \\
\hline Sleep(hours) & $\begin{array}{c}-0.021 \\
(0.002)\end{array}$ & $\begin{array}{c}-0.036 \\
(0.005)\end{array}$ & $\begin{array}{c}0.000 \\
(0.001)\end{array}$ & $\begin{array}{c}-0.002 \\
(0.004)\end{array}$ \\
\hline Eligible $\times$ Sleep(hours) & $\begin{array}{c}0.102 \\
(0.001)\end{array}$ & $\begin{array}{c}0.207 \\
(0.002)\end{array}$ & $\begin{array}{c}0.001 \\
(0.000)\end{array}$ & $\begin{array}{c}0.002 \\
(0.001)\end{array}$ \\
\hline Post & $\begin{array}{c}0.111 \\
(0.017)\end{array}$ & $\begin{array}{c}0.368 \\
(0.045)\end{array}$ & $\begin{array}{c}0.002 \\
(0.026)\end{array}$ & $\begin{array}{c}0.176 \\
(0.028)\end{array}$ \\
\hline Post $\times$ Sleep(hours) & $\begin{array}{c}0.013 \\
(0.002)\end{array}$ & $\begin{array}{c}0.013 \\
(0.006)\end{array}$ & $\begin{array}{c}0.004 \\
(0.004)\end{array}$ & $\begin{array}{c}0.002 \\
(0.004)\end{array}$ \\
\hline Post $\times$ Eligible & $\begin{array}{c}0.453 \\
(0.024)\end{array}$ & $\begin{array}{c}0.835 \\
(0.065)\end{array}$ & $\begin{array}{c}0.119 \\
(0.035)\end{array}$ & $\begin{array}{c}0.000 \\
(0.030)\end{array}$ \\
\hline Post $\times$ Eligible $\times$ Sleep(hours) & $\begin{array}{c}-\mathbf{- 0 . 0 7 1} \\
(\mathbf{0 . 0 0 3})\end{array}$ & $\begin{array}{c}-0.129 \\
(0.009)\end{array}$ & $\begin{array}{c}-0.013 \\
(0.005)\end{array}$ & $\begin{array}{c}-\mathbf{- 0 . 0 0 1} \\
(\mathbf{0 . 0 0 4 )}\end{array}$ \\
\hline $\begin{array}{l}\text { Observations } \\
\text { No. of mothers }\end{array}$ & $\begin{array}{l}58,732 \\
11,768\end{array}$ & $\begin{array}{l}54,494 \\
11,591\end{array}$ & $\begin{array}{c}49,322 \\
9,878\end{array}$ & $\begin{array}{c}26,204 \\
6,855\end{array}$ \\
\hline Outcome mean & 0.488 & 1.280 & 5.639 & 0.650 \\
\hline Outcome standard deviation & 0.499 & 1.483 & 0.662 & 0.476 \\
\hline
\end{tabular}

Notes: All specifications are estimated using OLS and include child's age dummies, child's health, mother's general health, mother's mental health, the number of children in the household, and whether mother is separated. Column (3) also includes father's sleep duration. The sample is restricted to years 1991-1997. The number of observations across outcomes varies due to data availability. Clustered standard errors on mother-child are in parentheses. 


\section{SUPPLEMENTARY MATERIAL (FOR ONLINE PUBLICATION)}

\section{A. Figures}

Figure A1. The Relationship Between Mother Having Enough Sleep and Mother Average Duration of Sleep

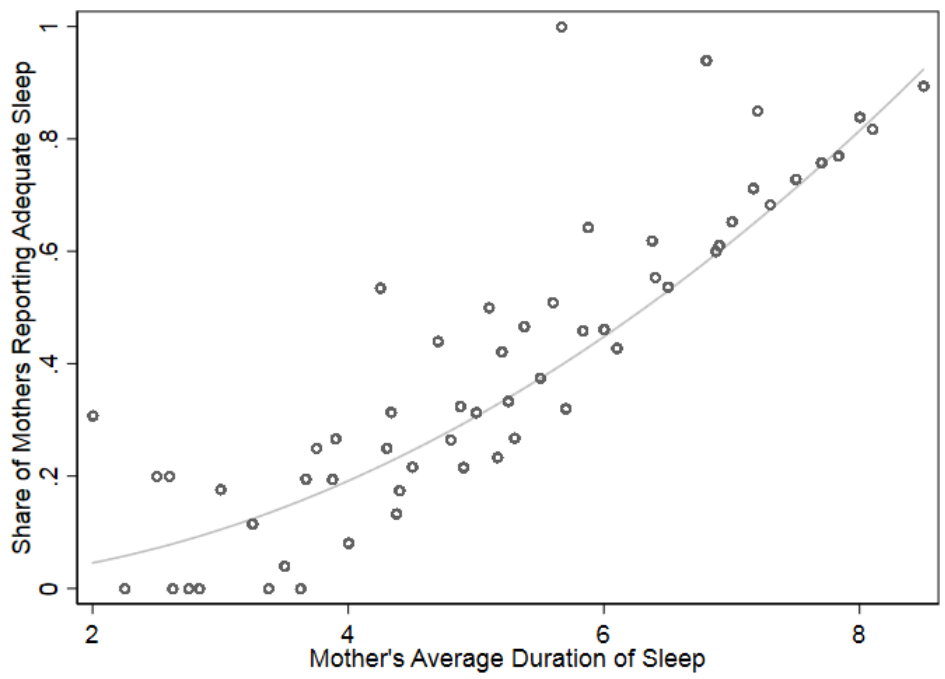

Notes: The figure is a scatter plot of mother having enough sleep against mother's average duration of sleep. To construct this scatter plot, we first average mother's average duration of sleep by mother-child pairs. We then plot the means of the y-variable within each average against the mean value of mother's average duration of sleep within each mother-child pair. The solid line shows the best quadratic fit estimated.

Figure A2. Child Sleep Duration by Age

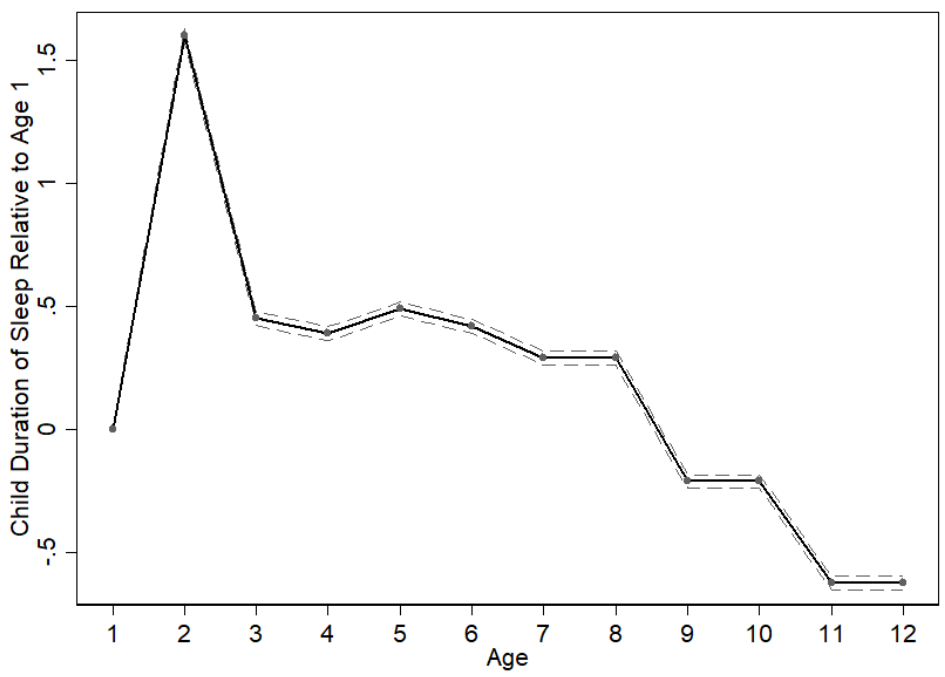

Notes: The figure represents the changes in child sleep duration per night relative to the first year of life by child age. 
Figure A3. Probability that the Child Has a Sleeping Routine by Age

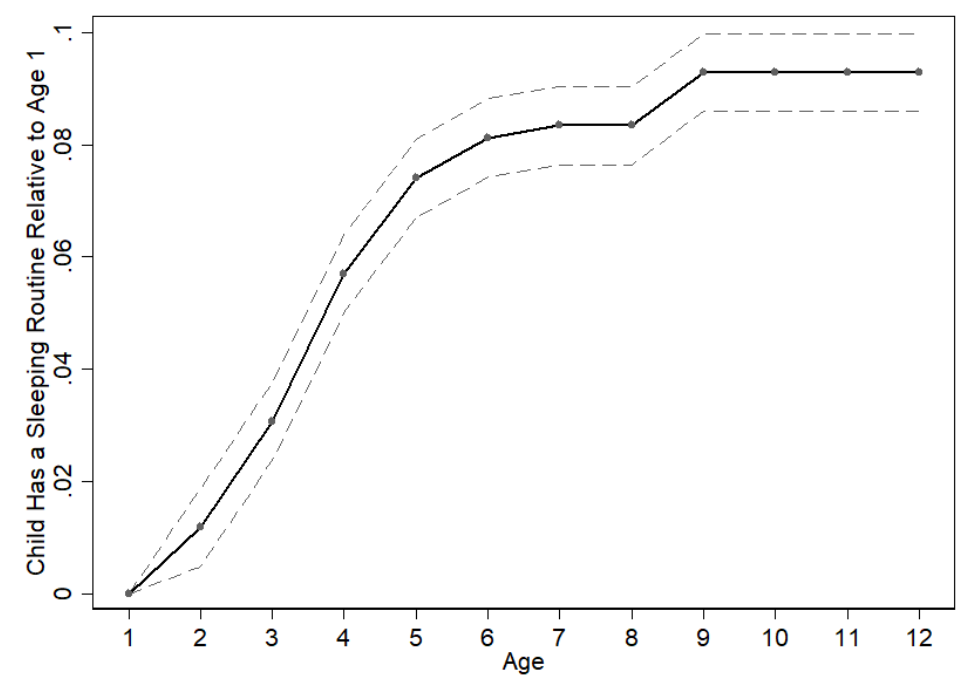

Notes: The figure represents the changes in the probability that the child has a sleeping routine relative to the first year of life by child age.

Figure A4. Distribution of Child's Duration of Sleep by Age
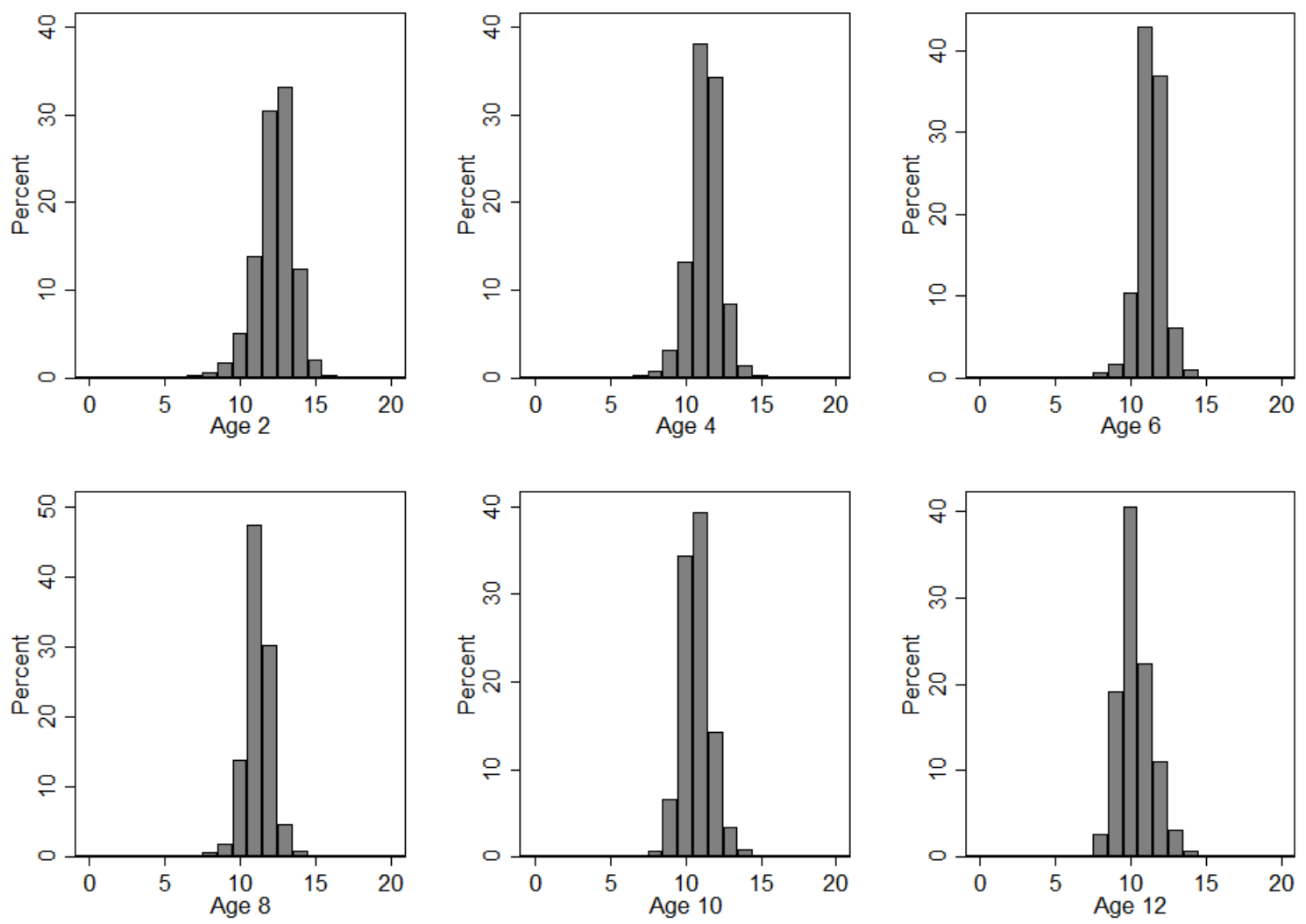

Notes: The figure represents the raw distribution of the ALSPAC children duration of sleep when they were 2, 4, 6,10 and 12 . 
Figure A5. Distribution of the Number of Times the Child Wakes up At Night by Age
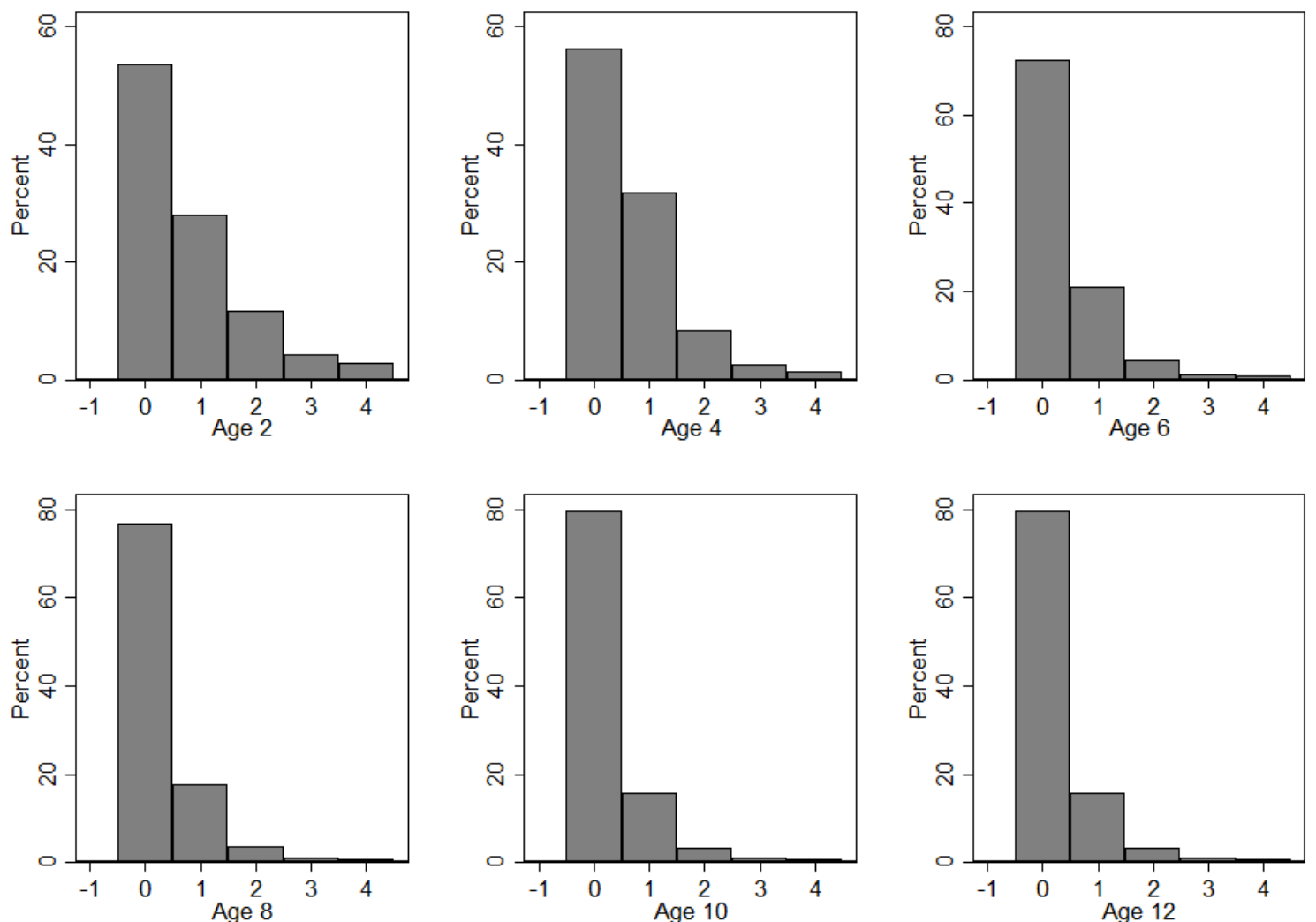

Notes: The figure represents the distribution of the number of times the ALSPAC children woke up at night when they were $2,4,6,8,10$ and 12 .

Figure A6. Normal Distribution of Mother's Average Duration of Sleep

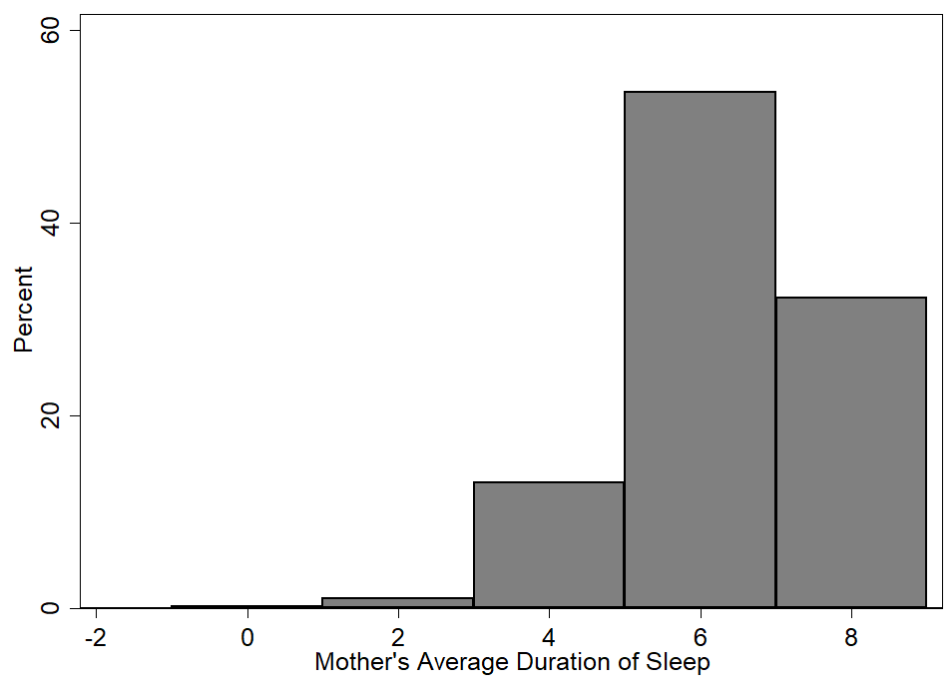

Notes: The figure represents the raw distribution of mothers' average duration of sleep per night in ALSPAC. 


\section{B. Tables}

Table A1. Raw Correlations Between Child Sleep Variables

\begin{tabular}{|c|c|c|c|c|}
\hline & $\begin{array}{c}\text { Child sleep } \\
\text { duration }\end{array}$ & $\begin{array}{l}\text { No. of times } \\
\text { child wakes } \\
\text { up at night }\end{array}$ & $\begin{array}{c}\text { Probability } \\
\text { that the child } \\
\text { wakes up at } \\
\text { night }\end{array}$ & $\begin{array}{l}\text { Child has a } \\
\text { regular } \\
\text { sleeping } \\
\text { routine } \\
\end{array}$ \\
\hline Child sleep duration & 1.000 & & & \\
\hline No. of times child wakes up at night & -0.041 & 1.000 & & \\
\hline Probability that the child wakes up at night & -0.011 & 0.837 & 1.000 & \\
\hline Child has a regular sleeping routine & 0.123 & -0.213 & -0.286 & 1.000 \\
\hline
\end{tabular}


Table A2. Raw Correlations of Child Sleep Duration between all the Different Timepoints

\begin{tabular}{|c|c|c|c|c|c|c|c|c|c|c|c|c|}
\hline & 1 & 2 & 3 & 4 & 5 & 6 & 7 & 8 & 9 & 10 & 11 & 12 \\
\hline Age 1 & 1.000 & & & & & & & & & & & \\
\hline Age 2 & 0.652 & 1.000 & & & & & & & & & & \\
\hline Age 3 & 0.599 & 0.764 & 1.000 & & & & & & & & & \\
\hline Age 4 & 0.535 & 0.656 & 0.818 & 1.000 & & & & & & & & \\
\hline Age 5 & 0.439 & 0.596 & 0.699 & 0.840 & 1.000 & & & & & & & \\
\hline Age 6 & 0.389 & 0.515 & 0.615 & 0.727 & 0.863 & 1.000 & & & & & & \\
\hline Age 7 & 0.357 & 0.473 & 0.521 & 0.646 & 0.753 & 0.875 & 1.000 & & & & & \\
\hline Age 8 & 0.253 & 0.447 & 0.479 & 0.549 & 0.670 & 0.759 & 0.887 & 1.000 & & & & \\
\hline Age 9 & 0.264 & 0.349 & 0.422 & 0.507 & 0.574 & 0.665 & 0.754 & 0.968 & 1.000 & & & \\
\hline Age 10 & 0.133 & 0.335 & 0.387 & 0.444 & 0.532 & 0.581 & 0.679 & 0.765 & 0.913 & 1.000 & & \\
\hline Age 11 & 0.128 & 0.201 & 0.344 & 0.404 & 0.460 & 0.527 & 0.574 & 0.663 & 0.780 & 0.881 & 1.000 & \\
\hline Age 12 & 0.163 & 0.132 & 0.316 & 0.376 & 0.439 & 0.481 & 0.575 & 0.575 & 0.780 & 0.780 & 1.000 & 1.000 \\
\hline
\end{tabular}

Notes: All correlations are significant at the $1 \%$ level. Child sleep duration is in hours. All the variables are reported by the mother. 
Table A3. Raw Correlations of Child Wakes Up Frequently between all the Different Timepoints

\begin{tabular}{|c|c|c|c|c|c|c|c|c|c|c|c|c|}
\hline & 1 & 2 & 3 & 4 & 5 & 6 & 7 & 8 & 9 & 10 & 11 & 12 \\
\hline Age 1 & 1,000 & & & & & & & & & & & \\
\hline Age 2 & 0.651 & 1,000 & & & & & & & & & & \\
\hline Age 3 & 0.549 & 0.707 & 1,000 & & & & & & & & & \\
\hline Age 4 & 0.490 & 0.612 & 0.756 & 1,000 & & & & & & & & \\
\hline Age 5 & 0.432 & 0.551 & 0.670 & 0.815 & 1,000 & & & & & & & \\
\hline Age 6 & 0.390 & 0.488 & 0.613 & 0.745 & 0.876 & 1,000 & & & & & & \\
\hline Age 7 & 0.346 & 0.444 & 0.548 & 0.689 & 0.81 & 0.918 & 1,000 & & & & & \\
\hline Age 8 & 0.303 & 0.396 & 0.504 & 0.626 & 0.759 & 0.857 & 0.954 & 1,000 & & & & \\
\hline Age 9 & 0.253 & 0.350 & 0.451 & 0.579 & 0.687 & 0.799 & 0.885 & 0.942 & 1,000 & & & \\
\hline Age 10 & 0.211 & 0.299 & 0.402 & 0.531 & 0.661 & 0.738 & 0.849 & 0.923 & 1,000 & 1,000 & & \\
\hline Age 11 & 0.174 & 0.255 & 0.341 & 0.480 & 0.614 & 0.719 & 0.777 & 0.885 & 1,000 & 1,000 & 1,000 & \\
\hline Age 12 & 0.119 & 0.226 & 0.286 & 0.408 & 0.569 & 0.667 & 0.777 & 0.777 & 1,000 & 1,000 & 1,000 & 1,000 \\
\hline
\end{tabular}

Notes: All correlations are significant at the $1 \%$ level. Child wakes up frequently is a dummy variable with (1) indicating that child wakes up more than 2 times per night. All the variables are reported by the mother. 
Table A4. Effect of Child Sleep Duration and Child Sleep Disruption on Parental Sleep Quality

\begin{tabular}{|c|c|c|c|c|c|c|}
\hline & $\begin{array}{c}\text { Mother's } \\
\text { sleep duration } \\
(1) \\
\end{array}$ & $\begin{array}{c}\text { Mother sleeps } \\
\text { less than } 6 \\
\text { hours } \\
(2) \\
\end{array}$ & $\begin{array}{c}\text { Mother has } \\
\text { enough sleep } \\
\text { (3) }\end{array}$ & $\begin{array}{c}\Delta \text { (Mother's } \\
\text { sleep } \\
\text { duration) } \\
(4) \\
\end{array}$ & $\begin{array}{c}\text { Mother's } \\
\text { sleep duration } \\
\text { (5 years } \\
\text { lagged) } \\
(5) \\
\end{array}$ & $\begin{array}{c}\text { Father's sleep } \\
\text { duration } \\
(6) \\
\end{array}$ \\
\hline $\begin{array}{l}\text { No. of times the child } \\
\text { wakes up at night }\end{array}$ & $\begin{array}{l}-0.105 \\
(0.007)\end{array}$ & $\begin{array}{c}0.023 \\
(0.002)\end{array}$ & $\begin{array}{l}-0.036 \\
(0.002)\end{array}$ & & $\begin{array}{c}0.010 \\
(0.015)\end{array}$ & $\begin{array}{l}-0.044 \\
(0.007)\end{array}$ \\
\hline Child's sleep duration & $\begin{array}{c}0.028 \\
(0.005)\end{array}$ & $\begin{array}{l}-0.009 \\
(0.001)\end{array}$ & $\begin{array}{c}0.007 \\
(0.002)\end{array}$ & & $\begin{array}{l}-0.006 \\
(0.008)\end{array}$ & $\begin{array}{c}0.009 \\
(0.004)\end{array}$ \\
\hline $\begin{array}{l}\Delta \text { (No. of times child } \\
\text { wakes up at night) }\end{array}$ & & & & $\begin{array}{l}-0.036 \\
(0.006)\end{array}$ & & \\
\hline $\begin{array}{l}\Delta \text { (Child's sleep } \\
\text { duration) }\end{array}$ & & & & $\begin{array}{c}0.099 \\
(0.004)\end{array}$ & & \\
\hline Mother/Father health & $\begin{array}{c}0.032 \\
(0.018)\end{array}$ & $\begin{array}{l}-0.001 \\
(0.004)\end{array}$ & $\begin{array}{c}0.035 \\
(0.006)\end{array}$ & & $\begin{array}{l}-0.064 \\
(0.025)\end{array}$ & $\begin{array}{c}0.031 \\
(0.020)\end{array}$ \\
\hline Mother/Father MH & $\begin{array}{c}0.022 \\
(0.001)\end{array}$ & $\begin{array}{l}-0.005 \\
(0.000)\end{array}$ & $\begin{array}{c}0.011 \\
(0.001)\end{array}$ & & $\begin{array}{l}-0.007 \\
(0.002)\end{array}$ & $\begin{array}{c}0.032 \\
(0.005)\end{array}$ \\
\hline Mother is separated & $\begin{array}{l}-0.030 \\
(0.018)\end{array}$ & $\begin{array}{c}0.002 \\
(0.005)\end{array}$ & $\begin{array}{c}0.008 \\
(0.006)\end{array}$ & & $\begin{array}{c}0.051 \\
(0.025)\end{array}$ & \\
\hline Child health & $\begin{array}{c}0.037 \\
(0.017)\end{array}$ & $\begin{array}{l}-0.008 \\
(0.004)\end{array}$ & $\begin{array}{l}-0.001 \\
(0.006)\end{array}$ & & $\begin{array}{c}0.002 \\
(0.023)\end{array}$ & $\begin{array}{c}0.012 \\
(0.016)\end{array}$ \\
\hline Environment: noise & $\begin{array}{l}-0.001 \\
(0.006)\end{array}$ & $\begin{array}{l}-0.001 \\
(0.002)\end{array}$ & $\begin{array}{c}0.003 \\
(0.002)\end{array}$ & & $\begin{array}{c}0.014 \\
(0.009)\end{array}$ & $\begin{array}{c}0.002 \\
(0.006)\end{array}$ \\
\hline Child shares bedroom & $\begin{array}{c}0.011 \\
(0.018)\end{array}$ & $\begin{array}{l}-0.003 \\
(0.005)\end{array}$ & $\begin{array}{c}0.009 \\
(0.006)\end{array}$ & & $\begin{array}{l}-0.115 \\
(0.021)\end{array}$ & $\begin{array}{c}0.018 \\
(0.018)\end{array}$ \\
\hline No. of children in $\mathrm{HH}$ & $\begin{array}{l}-0.151 \\
(0.011)\end{array}$ & $\begin{array}{c}0.033 \\
(0.003)\end{array}$ & $\begin{array}{l}-0.046 \\
(0.004)\end{array}$ & & $\begin{array}{l}-0.058 \\
(0.013)\end{array}$ & $\begin{array}{l}-0.058 \\
(0.010)\end{array}$ \\
\hline$\Delta$ (Mother's health) & & & & $\begin{array}{c}0.026 \\
(0.007)\end{array}$ & & \\
\hline$\Delta$ (Mother mental health) & & & & $\begin{array}{c}0.013 \\
(0.001)\end{array}$ & & \\
\hline$\Delta$ (Mother is separated) & & & & $\begin{array}{l}-0.053 \\
(0.012)\end{array}$ & & \\
\hline$\Delta$ (Child health) & & & & $\begin{array}{c}0.022 \\
(0.007)\end{array}$ & & \\
\hline$\Delta$ (Env: noise) & & & & $\begin{array}{c}0.007 \\
(0.005)\end{array}$ & & \\
\hline$\Delta($ Child shares bedroom $)$ & & & & $\begin{array}{l}-0.007 \\
(0.010)\end{array}$ & & \\
\hline$\Delta($ No. of children in $\mathrm{HH})$ & & & & $\begin{array}{l}-0.104 \\
(0.006)\end{array}$ & & \\
\hline Observations & 142,081 & 142,081 & 141,125 & 130,192 & 82,912 & 99,888 \\
\hline R-squared & 0.644 & 0.587 & 0.624 & 0.0497 & 0.450 & 0.742 \\
\hline No. of families & 11,935 & 11,935 & 11,857 & 11,935 & 11,910 & 8,501 \\
\hline Child age dummies & Yes & Yes & Yes & Yes & Yes & Yes \\
\hline Mother-child FE & Yes & Yes & Yes & Yes & Yes & Yes \\
\hline
\end{tabular}

Notes: All specifications are estimated using OLS and include mother-child fixed effects. Clustered standard errors in parentheses. 
Table A5. Effect of Child Sleep Duration and Child Sleep Disruption on Parental Sleep Quality (Cross-section)

\begin{tabular}{|c|c|c|c|c|}
\hline & $\begin{array}{c}\text { Mother's sleep } \\
\text { duration } \\
\text { (1) } \\
\end{array}$ & $\begin{array}{c}\text { Mother sleeps less } \\
\text { than } 6 \text { hours } \\
(2) \\
\end{array}$ & $\begin{array}{c}\text { Mother has enough } \\
\text { sleep } \\
\text { (3) }\end{array}$ & $\begin{array}{c}\text { Father's sleep } \\
\text { duration } \\
\text { (4) }\end{array}$ \\
\hline $\begin{array}{l}\text { No. of times the child } \\
\text { wakes up at night }\end{array}$ & $\begin{array}{l}-0.206 \\
(0.011)\end{array}$ & $\begin{array}{c}0.042 \\
(0.003)\end{array}$ & $\begin{array}{l}-0.063 \\
(0.004)\end{array}$ & $\begin{array}{l}-0.110 \\
(0.013)\end{array}$ \\
\hline Child's sleep duration & $\begin{array}{c}0.092 \\
(0.007)\end{array}$ & $\begin{array}{c}-0.018 \\
(0.002)\end{array}$ & $\begin{array}{c}0.021 \\
(0.002)\end{array}$ & $\begin{array}{c}0.047 \\
(0.008)\end{array}$ \\
\hline Observations & 142,081 & 142,081 & 141,125 & 99,888 \\
\hline R-squared & 0.093 & 0.075 & 0.091 & 0.029 \\
\hline Child controls & Yes & Yes & Yes & Yes \\
\hline Parent controls & Yes & Yes & Yes & Yes \\
\hline Mother-child FE & No & No & No & No \\
\hline No of families & 11,935 & 11,935 & 11,857 & 8,501 \\
\hline
\end{tabular}

Notes: All specifications are estimated using OLS. Specifications (1) to (3) control for child's age dummies, child health, mother's general health, mother's mental health, the number of children in the household, whether mother is separated, and environmental triggers (noise and whether child shares bedroom). Specification (4) control for the same child covariates but includes father's general health, father's mental health, the number of children in the household, and the same environmental triggers. Clustered standard errors in parentheses. 
Table A6. Effect of Sleeping 6 Hours and Getting Enough Sleep on Mother's Economic Performance

\begin{tabular}{|c|c|c|c|c|}
\hline & $\begin{array}{c}\text { Probability to } \\
\text { work } \\
(1) \\
\end{array}$ & $\begin{array}{c}\log \\
\text { (Hours worked) } \\
(2) \\
\end{array}$ & $\begin{array}{c}\text { Log } \\
\text { (HH income) } \\
(3) \\
\end{array}$ & $\begin{array}{l}\text { Satisfied } \\
\text { with job } \\
(4)\end{array}$ \\
\hline \multicolumn{5}{|c|}{ Panel A: Instrumental variables (2SLS) } \\
\hline Mother sleep less than 6 hours & $\begin{array}{c}-0.128 \\
(0.090)\end{array}$ & $\begin{array}{c}-0.236 \\
(0.257)\end{array}$ & $\begin{array}{c}-0.110 \\
(0.077)\end{array}$ & $\begin{array}{c}-0.019 \\
(0.146)\end{array}$ \\
\hline Observations & 142,081 & 133,297 & 121,595 & 78,061 \\
\hline No. of mothers & 11,933 & 11,811 & 10,501 & 9,142 \\
\hline Kleibergen-Paap statistic & 83.66 & 79.71 & 85.88 & 33.93 \\
\hline \multicolumn{5}{|c|}{ Panel B: Instrumental variables (2SLS) } \\
\hline Mother has enough sleep & $\begin{array}{c}0.206 \\
(0.065)\end{array}$ & $\begin{array}{c}0.608 \\
(0.181)\end{array}$ & $\begin{array}{c}0.719 \\
(0.069)\end{array}$ & $\begin{array}{c}0.008 \\
(0.109)\end{array}$ \\
\hline Observations & 141,125 & 132,574 & 121,055 & 77,810 \\
\hline No. of mothers & 11,857 & 11,747 & 10,472 & 9,118 \\
\hline Kleibergen-Paap statistic & 111.2 & 111.6 & 121.8 & 36.16 \\
\hline
\end{tabular}

Notes: Specifications in Panel A and B are estimated using 2SLS. They include mother-child fixed effects, child's age dummies, child health, mother's general health, mother's mental health, the number of children in the household, whether mother is separated, and environmental triggers (noise and whether child shares the bedroom). Specifications in column (3) also control for father's sleep duration. The number of observations across outcomes varies due to data availability. Clustered standard errors on mother-child are in parentheses. 
Table A7. Effect of Mother's and Father's Sleep Duration on Parent's Economic Performance

$\begin{array}{ccccccc}\text { Father } & \text { Log } & \text { Father } & \text { Log } & \text { Log } & \text { Log } & \text { Log } \\ \text { probability } & (\mathrm{HH} & \text { probability } & (\mathrm{HH} & (\mathrm{HH} & (\mathrm{HH} & (\mathrm{HH} \\ \text { to work } & \text { income }) & \text { to work } & \text { income }) & \text { income }) & \text { income }) & \text { income })\end{array}$

(1) (2)

(3)

Correlation (OLS)

(4)

(5)

(6)

(7)

Instrumental variables (2SLS)

Mother Sleep (hours)

$\begin{array}{cccc} & & & \\ -0.001 & 0.003 & 0.072 & 0.197 \\ (0.002) & (0.003) & (0.049) & (0.059)\end{array}$

$\begin{array}{cc}0.032 & 0.032 \\ (0.018) & (0.019) \\ & -0.002 \\ & (0.003)\end{array}$

Father Sleep (hours)

Household Sleep (hours)

0.025

(0.013)

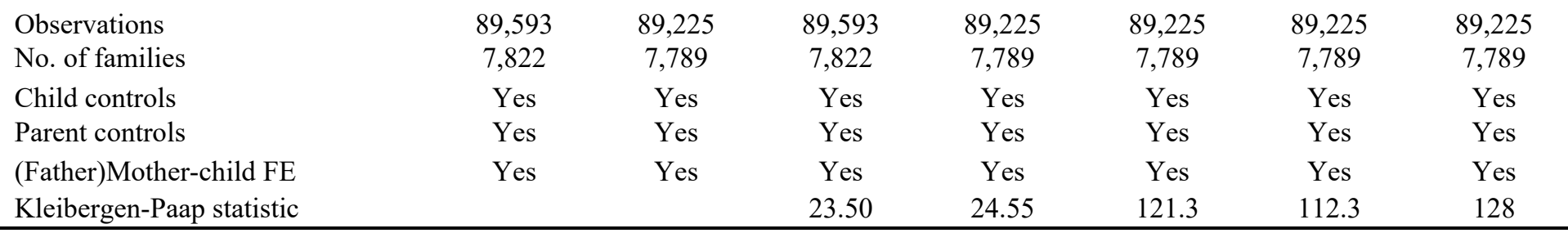

Notes: Specifications in columns (1) and (2) are estimated using OLS, and include father fixed effects, child's age dummies, child health, father's general health, father's mental health, the number of children in the household, and environmental triggers (noise and whether child shares the bedroom). Specifications in columns (3) and (4) include the same covariates but are estimated using 2SLS. Specifications in columns (5) and (6) include mother and father sleep. Column (7) aggregates mother and father sleep at the household level and instruments household sleep with child sleep disturbances and child sleep duration. The number of observations across outcomes varies due to data availability. Clustered standard errors on father-child are in parentheses. 
Table A8. Effect of Mother Sleep Duration on Mother's Economic Performance (using the same sample across specifications)

\begin{tabular}{lcccc}
\hline & $\begin{array}{c}\text { Probability to } \\
\text { work } \\
(1)\end{array}$ & $\begin{array}{c}\text { Log } \\
\text { (Hours worked) } \\
(2)\end{array}$ & $\begin{array}{c}\text { Log } \\
\text { (HH income) } \\
(3)\end{array}$ & $\begin{array}{c}\text { Satisfied } \\
\text { with job } \\
\text { jos }\end{array}$ \\
\hline Sleep (hours) & 0.033 & 0.068 & 0.109 & 0.003 \\
& $(0.021)$ & $(0.062)$ & $(0.018)$ & $(0.035)$ \\
Observations & 114,953 & 114,953 & 114,953 & 78,061 \\
No. of mothers & 10,459 & 10,459 & 10,459 & 9,325 \\
Outcome mean & 0.591 & 1.631 & 5.754 & 0.660 \\
Outcome standard & 0.491 & 1.511 & 0.685 & 0.479 \\
deviation & 108.8 & 108.8 & 133.3 & 74.96 \\
Kleibergen-Paap statistic & & & & \\
\hline Notes: Specifications & & & \\
\hline
\end{tabular}

Notes: Specifications are estimated using 2SLS and include mother-child fixed effects, child's age dummies, child health, mother's general health, mother's mental health, the number of children in the household, whether mother is separated, and environmental triggers (noise and whether child shares the bedroom). Specification in column (3) also includes father's sleep duration. Clustered standard errors on mother-child are in parentheses. 
Table A9. Effect of Mother Sleep Duration on Mother's Economic Performance (restricting the sample to mothers with only one child)

\begin{tabular}{|c|c|c|c|c|}
\hline & $\begin{array}{l}\text { Probability to } \\
\text { work } \\
\text { (1) } \\
\end{array}$ & $\begin{array}{c}\text { Log } \\
\text { (Hours worked) } \\
(2) \\
\end{array}$ & $\begin{array}{c}\text { Log } \\
\text { (HH income) } \\
(3) \\
\end{array}$ & $\begin{array}{c}\text { Satisfied } \\
\text { with job } \\
\text { (4) } \\
\end{array}$ \\
\hline Sleep (hours) & $\begin{array}{c}0.020 \\
(0.027)\end{array}$ & $\begin{array}{c}0.082 \\
(0.076)\end{array}$ & $\begin{array}{c}0.219 \\
(0.032)\end{array}$ & $\begin{array}{c}0.069 \\
(0.041)\end{array}$ \\
\hline Observations & 46,578 & 43,608 & 36,668 & 26,838 \\
\hline No. of mothers & 4,923 & 4,850 & 4,404 & 3,704 \\
\hline Outcome mean & 0.591 & 1.631 & 5.754 & 0.660 \\
\hline $\begin{array}{l}\text { Outcome standard } \\
\text { deviation }\end{array}$ & 0.491 & 1.511 & 0.685 & 0.479 \\
\hline Kleibergen-Paap statistic & 95.66 & 94.62 & 91.38 & 50.27 \\
\hline
\end{tabular}

Notes: Specifications are estimated using 2SLS and include mother-child fixed effects, child's age dummies, child health, mother's general health, mother's mental health, whether mother is separated, and environmental triggers (noise and whether child shares the bedroom). Specification in column (3) also includes father's sleep duration. Clustered standard errors on mother-child are in parentheses. 
Table A10. Plausibly Exogenous Estimations

\begin{tabular}{|c|c|c|c|c|}
\hline & $\begin{array}{c}\text { Probability to } \\
\text { work } \\
\text { (1) } \\
\end{array}$ & $\begin{array}{c}\log \\
\text { (Hours worked) } \\
(2) \\
\end{array}$ & $\begin{array}{c}\text { Log } \\
\text { (HH income) } \\
(3) \\
\end{array}$ & $\begin{array}{c}\text { Satisfied } \\
\text { with job } \\
(4)\end{array}$ \\
\hline Sleep (hours) & {$[-0.047 ; 0.074]$} & {$[-0.109 ; 0.149]$} & {$[-0.038 ; 0.114]$} & {$[-0.075 ; 0.079]$} \\
\hline Observations & 142,081 & 133,297 & 121,595 & 78,061 \\
\hline No. of mothers & 11,935 & 11,832 & 10,610 & 9,325 \\
\hline Outcome mean & 0.591 & 1.631 & 5.754 & 0.640 \\
\hline Outcome standard deviation & 0.491 & 1.511 & 0.685 & 0.479 \\
\hline
\end{tabular}

Notes: This table replicates Table 3 using plausible exogenous estimations developed by Conley et al. (2012). The method used refers to the union of confidence interval approach (UCI). The table presents the estimated bounds obtained. 
Table A11. Effect of Mother Labour Force Participation on Child Sleep Patterns (Simultaneity Bias)

\begin{tabular}{|c|c|c|c|}
\hline & & $\begin{array}{c}\text { Child Sleep Duration } \\
\text { (1) }\end{array}$ & $\begin{array}{l}\text { Frequency Child Wakes Up } \\
\text { at Night } \\
\text { (2) }\end{array}$ \\
\hline \multirow[t]{2}{*}{ Age 1} & Mother works & $\begin{array}{c}0.008 \\
(0.013)\end{array}$ & $\begin{array}{l}-0.075 \\
(0.030)\end{array}$ \\
\hline & Observations & 11,741 & 11,741 \\
\hline \multirow[t]{2}{*}{ Age 2} & Mother works & $\begin{array}{l}-0.038 \\
(0.045)\end{array}$ & $\begin{array}{l}-0.070 \\
(0.052)\end{array}$ \\
\hline & Observations & 11,741 & 11,741 \\
\hline \multirow[t]{2}{*}{ Age 3} & Mother works & $\begin{array}{c}0.098 \\
(0.035)\end{array}$ & $\begin{array}{l}-0.054 \\
(0.039)\end{array}$ \\
\hline & Observations & 11,741 & 11,741 \\
\hline \multirow[t]{2}{*}{ Age 4} & Mother works & $\begin{array}{c}0.006 \\
(0.009)\end{array}$ & $\begin{array}{l}-0.003 \\
(0.016)\end{array}$ \\
\hline & Observations & 11,741 & 11,741 \\
\hline \multirow[t]{2}{*}{ Age 5} & Mother works & $\begin{array}{c}0.001 \\
(0.009)\end{array}$ & $\begin{array}{l}-0.014 \\
(0.014)\end{array}$ \\
\hline & Observations & 11,768 & 11,768 \\
\hline \multirow[t]{2}{*}{ Age 6} & Mother works & $\begin{array}{c}0.007 \\
(0.012)\end{array}$ & $\begin{array}{l}-0.018 \\
(0.015)\end{array}$ \\
\hline & Observations & 11,863 & 11,863 \\
\hline \multirow[t]{2}{*}{ Age 7} & Mother works & $\begin{array}{l}-0.000 \\
(0.011)\end{array}$ & $\begin{array}{l}-0.036 \\
(0.013)\end{array}$ \\
\hline & Observations & 11,874 & 11,874 \\
\hline \multirow[t]{2}{*}{ Age 8} & Mother works & $\begin{array}{l}-0.011 \\
(0.011)\end{array}$ & $\begin{array}{l}-0.048 \\
(0.013)\end{array}$ \\
\hline & Observations & 11,922 & 11,894 \\
\hline \multirow[t]{2}{*}{ Age 9} & Mother works & $\begin{array}{l}-0.011 \\
(0.011)\end{array}$ & $\begin{array}{l}-0.047 \\
(0.012)\end{array}$ \\
\hline & Observations & 11,922 & 11,922 \\
\hline \multirow[t]{2}{*}{ Age 10} & Mother works & $\begin{array}{l}-0.036 \\
(0.015)\end{array}$ & $\begin{array}{l}-0.047 \\
(0.012)\end{array}$ \\
\hline & Observations & 11,925 & 11,928 \\
\hline \multirow[t]{2}{*}{ Age 11} & Mother works & $\begin{array}{l}-0.040 \\
(0.014)\end{array}$ & $\begin{array}{l}-0.052 \\
(0.014)\end{array}$ \\
\hline & Observations & 11,933 & 11,933 \\
\hline \multirow[t]{2}{*}{ Age 12} & Mother works & $\begin{array}{l}-0.077 \\
(0.017)\end{array}$ & $\begin{array}{l}-0.051 \\
(0.013)\end{array}$ \\
\hline & Observations & 11,935 & 11,935 \\
\hline
\end{tabular}

Notes: Specifications are estimated using OLS and include mother's sleep duration, child's age dummies, child health, mother's general health, mother's mental health, the number of children in the household, whether mother is separated, environmental triggers (noise and whether child shares the bedroom), life events, father characteristics, parenting style and child emotional health, child cognitive performance and child behaviours. Clustered standard errors on mother-child are in parentheses. 
Table A12. Effect of Mother Sleep Duration on Mother's Economic Performance (with child sleep duration used as a control, rather than an instrument)

\begin{tabular}{lcccc}
\hline & $\begin{array}{c}\text { Probability to } \\
\text { work } \\
(1)\end{array}$ & $\begin{array}{c}\text { Log } \\
\text { (Hours worked) } \\
(2)\end{array}$ & $\begin{array}{c}\text { Log } \\
\text { (HH income) } \\
(3)\end{array}$ & $\begin{array}{c}\text { Satisfied } \\
\text { with job } \\
(4)\end{array}$ \\
\hline Sleep (hours) & 0.119 & 0.388 & 0.240 & -0.001 \\
& $(0.024)$ & $(0.069)$ & $(0.022)$ & $(0.037)$ \\
& 142,081 & 133,297 & 121,595 & 78,061 \\
Observations & 11,935 & 11,832 & 10,610 & 9,325 \\
No. of mothers & 0.591 & 1.631 & 5.754 & 0.660 \\
$\begin{array}{l}\text { Outcome mean } \\
\text { Outcome standard } \\
\text { deviation }\end{array}$ & 0.491 & 1.511 & 0.685 & 0.479 \\
Kleibergen-Paap statistic & 213.1 & 200.5 & 258.6 & 74.96 \\
\hline $\begin{array}{l}\text { Notes: } \text { Specifications are estimated using 2SLS and include mother-child fixed effects, child's age dummies, child } \\
\text { health, mother's general health, mother's mental health, the number of children in the household, whether mother }\end{array}$ \\
$\begin{array}{l}\text { is separated, and environmental triggers (noise and whether child shares the bedroom). Specification in column } \\
\text { (3) also includes father's sleep duration. The number of observations across outcomes varies due to data }\end{array}$ \\
availability. Clustered standard errors on mother-child are in parentheses.
\end{tabular}


Table A13. Effect of Mother Sleep Duration on Mother's Economic Performance (IV probit)

\begin{tabular}{lcc}
\hline \hline & $\begin{array}{c}\text { Probability to } \\
\text { work }\end{array}$ & $\begin{array}{c}\text { Satisfied } \\
\text { with job } \\
(4)\end{array}$ \\
\hline Panel A: Correlation (probit) & $(1)$ & -0.007 \\
Sleep (hours) & 0.011 & $(0.008)$ \\
& $(0.006)$ & \\
Panel B: Instrumental variables (IV probit) & & 0.006 \\
Sleep (hours) & 0.056 & $(0.030)$ \\
& $(0.021)$ & \\
& & 78,061 \\
Observations & 142,081 & 9,325 \\
No. of mothers & 11,935 & 0.660 \\
Outcome mean & 0.591 & 0.479 \\
Outcome standard deviation & 0.491 & \\
\hline
\end{tabular}

Notes: Specifications in Panel A are estimated using probit regressions, and include mother-child fixed effects, child's age dummies, child health, mother's general health, mother's mental health, the number of children in the household, whether mother is separated, and environmental triggers (noise and whether child shares the bedroom). Specifications in Panel B include the same covariates but are estimated using instrumental probit regressions. The number of observations across outcomes varies due to data availability. Clustered standard errors on mother-child are in parentheses. 
Table A14. Effect of Mother Sleep Duration on Mother Economic Performance (Two-way Clustering)

\begin{tabular}{|c|c|c|c|c|}
\hline & $\begin{array}{c}\text { Probability to } \\
\text { work } \\
(1)\end{array}$ & $\begin{array}{c}\log \\
\text { (Hours worked) } \\
(2) \\
\end{array}$ & $\begin{array}{c}\text { Log } \\
\text { (HH income) } \\
(3)\end{array}$ & $\begin{array}{l}\text { Satisfied } \\
\text { with job } \\
(4)\end{array}$ \\
\hline \multicolumn{5}{|l|}{ Panel A: Correlation (OLS) } \\
\hline Sleep (hours) & $\begin{array}{c}0.010 \\
(0.001)\end{array}$ & $\begin{array}{c}0.028 \\
(0.003)\end{array}$ & $\begin{array}{c}0.016 \\
(0.001)\end{array}$ & $\begin{array}{c}-0.004 \\
(0.002)\end{array}$ \\
\hline \multicolumn{5}{|c|}{ Panel B: Instrumental variables (2SLS) } \\
\hline Sleep (hours) & $\begin{array}{c}0.050 \\
(0.023)\end{array}$ & $\begin{array}{c}0.140 \\
(0.070)\end{array}$ & $\begin{array}{c}0.099 \\
(0.045)\end{array}$ & $\begin{array}{c}0.003 \\
(0.036)\end{array}$ \\
\hline Observations & 142,081 & 133,297 & 121,595 & 78,061 \\
\hline No. of mothers & 11,935 & 11,832 & 10,610 & 9,325 \\
\hline Outcome mean & 0.591 & 1.631 & 5.754 & 0.660 \\
\hline Outcome standard deviation & 0.491 & 1.511 & 0.685 & 0.479 \\
\hline Kleibergen-Paap statistic & 23.67 & 24.29 & 26.76 & 8.334 \\
\hline
\end{tabular}

Notes: Specifications in Panel A are estimated using OLS, and include mother-child fixed effects, child's age dummies, child health, mother's general health, mother's mental health, the number of children in the household, whether mother is separated, and environmental triggers (noise and whether child shares the bedroom). Specifications in column (3) also include father sleep duration. Specifications in Panel B include the same covariates but are estimated using 2SLS. The number of observations across outcomes varies due to data availability. Clustered standard errors on mother-child and year are in parentheses. 
Table A15. Effect of Mother Satisfaction with Neighbours on Mother Economic Performance

\begin{tabular}{|c|c|c|c|c|}
\hline & $\begin{array}{c}\text { Probability to } \\
\text { work } \\
(1)\end{array}$ & $\begin{array}{c}\text { Log } \\
\text { (Hours worked) } \\
(2) \\
\end{array}$ & $\begin{array}{c}\log \\
\text { (HH income) } \\
(3)\end{array}$ & $\begin{array}{l}\text { Satisfied } \\
\text { with job } \\
(4)\end{array}$ \\
\hline \multicolumn{5}{|l|}{ Instrumental variables (2SLS) } \\
\hline Mother's satisfaction with neighbours & $\begin{array}{c}0.158 \\
(0.209)\end{array}$ & $\begin{array}{c}0.826 \\
(0.537)\end{array}$ & $\begin{array}{c}1.266 \\
(0.475)\end{array}$ & $\begin{array}{c}-0.518 \\
(0.386)\end{array}$ \\
\hline Observations & 140,841 & 132,291 & 120,845 & 77,676 \\
\hline No. of mothers & 11,822 & 11,711 & 10,446 & 9,102 \\
\hline Outcome mean & 0.591 & 1.631 & 5.754 & 0.640 \\
\hline Outcome standard deviation & 0.491 & 1.511 & 0.685 & 0.479 \\
\hline Kleibergen-Paap statistic & 3.014 & 3.750 & 6.286 & 2.512 \\
\hline
\end{tabular}

Notes: Regressions are estimated using 2SLS, and include mother-child fixed effects, child's age dummies, child health, mother's general health, mother's mental health, the number of children in the household, whether mother is separated, and environmental triggers (noise and whether child shares the bedroom). Column (3) also controls for father's sleep duration. Mother satisfaction with neighbours is instrumented using the number of times the child wakes up and child sleep duration. The number of observations across outcomes varies due to data availability. Clustered standard errors on mother-child are in parentheses. 
Table A16. Effect of Mother Sleep Duration on Mother Economic Performance (Excluding Outliers)

\begin{tabular}{|c|c|c|c|c|}
\hline & $\begin{array}{c}\text { Probability to } \\
\text { work } \\
(1)\end{array}$ & $\begin{array}{c}\log \\
\text { (Hours worked) } \\
(2) \\
\end{array}$ & $\begin{array}{c}\text { Log } \\
\text { (HH income) } \\
(3)\end{array}$ & $\begin{array}{l}\text { Satisfied } \\
\text { with job } \\
(4)\end{array}$ \\
\hline \multicolumn{5}{|l|}{ Panel A: Correlation (OLS) } \\
\hline Sleep (hours) & $\begin{array}{c}0.011 \\
(0.002)\end{array}$ & $\begin{array}{c}0.029 \\
(0.005)\end{array}$ & $\begin{array}{c}0.019 \\
(0.002)\end{array}$ & $\begin{array}{l}-0.004 \\
(0.003)\end{array}$ \\
\hline \multicolumn{5}{|c|}{ Panel B: Instrumental variables (2SLS) } \\
\hline Sleep (hours) & $\begin{array}{c}0.053 \\
(0.023)\end{array}$ & $\begin{array}{c}0.142 \\
(0.067)\end{array}$ & $\begin{array}{c}0.131 \\
(0.020)\end{array}$ & $\begin{array}{c}0.014 \\
(0.039)\end{array}$ \\
\hline Observations & 140,663 & 131,971 & 120,407 & 77,482 \\
\hline No. of mothers & 11,922 & 11,819 & 10,600 & 9,311 \\
\hline Outcome mean & 0.591 & 1.631 & 5.754 & 0.660 \\
\hline Outcome standard deviation & 0.491 & 1.511 & 0.685 & 0.479 \\
\hline Kleibergen-Paap statistic & 129.4 & 121.7 & 140.7 & 45.38 \\
\hline
\end{tabular}

Notes: Specifications in Panel A are estimated using OLS, and include mother-child fixed effects, child's age dummies, child health, mother's general health, mother's mental health, the number of children in the household, whether mother is separated, and environmental triggers (noise and whether child shares the bedroom). Specifications in column (3) also include father sleep duration. Specifications in Panel B include the same covariates but are estimated using 2SLS. The number of observations across outcomes varies due to data availability. We have excluded mother reporting sleeping 2 hours or less on average per night. Clustered standard errors on mother-child are in parentheses. 
Table A17: Effect of Mother's Sleep in the Long Term

\begin{tabular}{|c|c|c|c|c|}
\hline & $\begin{array}{c}\text { Probability to } \\
\text { work } \\
(1) \\
\end{array}$ & $\begin{array}{l}\text { Log (Hours } \\
\text { worked) } \\
(2) \\
\end{array}$ & $\begin{array}{c}\log (\mathrm{HH} \\
\text { income }) \\
(3) \\
\end{array}$ & $\begin{array}{c}\text { Satisfied with } \\
\text { job } \\
(4) \\
\end{array}$ \\
\hline \multicolumn{5}{|l|}{ Panel A: Baseline Results } \\
\hline Sleep (hours) & $\begin{array}{c}0.050 \\
(0.021)\end{array}$ & $\begin{array}{c}0.140 \\
(0.060)\end{array}$ & $\begin{array}{c}0.099 \\
(0.018)\end{array}$ & $\begin{array}{c}0.003 \\
(0.035)\end{array}$ \\
\hline \multicolumn{5}{|c|}{ Panel B: Distributed lag model } \\
\hline Sleep (hours) - 1 year prior & $\begin{array}{c}0.039 \\
(0.017)\end{array}$ & $\begin{array}{c}0.134 \\
(0.051)\end{array}$ & $\begin{array}{c}0.154 \\
(0.019)\end{array}$ & $\begin{array}{c}0.049 \\
(0.023)\end{array}$ \\
\hline Sleep (hours) -2 years prior & $\begin{array}{c}0.010 \\
(0.015)\end{array}$ & $\begin{array}{c}0.069 \\
(0.044)\end{array}$ & $\begin{array}{c}0.112 \\
(0.015)\end{array}$ & $\begin{array}{c}0.047 \\
(0.020)\end{array}$ \\
\hline Sleep (hours) -3 years prior & $\begin{array}{c}0.003 \\
(0.012)\end{array}$ & $\begin{array}{c}0.017 \\
(0.036)\end{array}$ & $\begin{array}{c}0.082 \\
(0.014)\end{array}$ & $\begin{array}{c}0.024 \\
(0.018)\end{array}$ \\
\hline Sleep (hours) -4 years prior & $\begin{array}{c}0.008 \\
(0.011)\end{array}$ & $\begin{array}{c}0.014 \\
(0.033)\end{array}$ & $\begin{array}{c}0.045 \\
(0.013)\end{array}$ & $\begin{array}{c}0.015 \\
(0.016)\end{array}$ \\
\hline Sleep (hours) -5 years prior & $\begin{array}{l}-0.002 \\
(0.010)\end{array}$ & $\begin{array}{c}0.019 \\
(0.030)\end{array}$ & $\begin{array}{c}0.044 \\
(0.012)\end{array}$ & $\begin{array}{c}0.001 \\
(0.015)\end{array}$ \\
\hline Panel C: Controlling for ne & & & & \\
\hline Sleep (hours) -5 years prior & $\begin{array}{c}0.031 \\
(0.018)\end{array}$ & $\begin{array}{c}0.090 \\
(0.054)\end{array}$ & $\begin{array}{c}0.036 \\
(0.018)\end{array}$ & $\begin{array}{c}0.006 \\
(0.024)\end{array}$ \\
\hline $\begin{array}{l}\text { New children in the } \mathrm{HH} \\
\text { (between } \mathrm{t}-5 \text { and } \mathrm{t} \text { ) }\end{array}$ & $\begin{array}{l}-0.037 \\
(0.008)\end{array}$ & $\begin{array}{l}-0.065 \\
(0.024)\end{array}$ & $\begin{array}{l}-0.018 \\
(0.010)\end{array}$ & $\begin{array}{l}-0.002 \\
(0.013)\end{array}$ \\
\hline $\begin{array}{l}\text { Observations } \\
\text { No. of mothers }\end{array}$ & $\begin{array}{l}82,469 \\
11,874\end{array}$ & $\begin{array}{l}78,038 \\
11,598\end{array}$ & $\begin{array}{l}71,702 \\
10,559\end{array}$ & $\begin{array}{c}51,532 \\
8,863\end{array}$ \\
\hline Outcome mean & 0.651 & 1.841 & 5.810 & 0.635 \\
\hline Outcome standard deviation & 0.476 & 1.490 & 0.690 & 0.481 \\
\hline Kleibergen-Paap statistic & 126.2 & 113.3 & 142.7 & 87.73 \\
\hline
\end{tabular}

Notes: Specifications in Panel A are the baseline results presented in Table 3, and include mother-child fixed effects, child's age dummies, child health, mother's general health, mother's mental health, the number of children in the household, whether mother is separated, and environmental triggers (noise and whether child shares the bedroom). Column (3) also includes father sleep duration. Specifications in Panel B are estimated using a distributed lag model instrumenting for each lag with the corresponding lag of the child sleep instruments. Specifications in Panel C replicate the baseline results presented in Table 5 but control for the presence of new children in the household between $t$ and $t+5$. The number of observations across outcomes varies due to data availability. Clustered standard errors on mother-child are in parentheses. 
Table A18. Effect of Mother's Sleep in the Long Term - Controlling for Current Health Problems

\begin{tabular}{|c|c|c|c|c|}
\hline & $\begin{array}{c}\text { Probability to } \\
\text { work } \\
\text { (1) }\end{array}$ & $\begin{array}{l}\text { Log (Hours } \\
\text { worked) } \\
(2) \\
\end{array}$ & $\begin{array}{c}\log (\mathrm{HH} \\
\text { income) } \\
(3) \\
\end{array}$ & $\begin{array}{c}\text { Satisfied with } \\
\text { job } \\
(4) \\
\end{array}$ \\
\hline \multicolumn{5}{|l|}{ Panel A: Baseline Results } \\
\hline Sleep (hours) -5 years prior & $\begin{array}{c}0.031 \\
(0.018)\end{array}$ & $\begin{array}{c}0.090 \\
(0.054)\end{array}$ & $\begin{array}{c}0.038 \\
(0.016)\end{array}$ & $\begin{array}{c}0.006 \\
(0.024)\end{array}$ \\
\hline \multicolumn{5}{|c|}{ Panel B: Controlling for health problems } \\
\hline Sleep (hours) -5 years prior & $\begin{array}{c}0.030 \\
(0.018)\end{array}$ & $\begin{array}{c}0.089 \\
(0.054)\end{array}$ & $\begin{array}{c}0.031 \\
(0.019)\end{array}$ & $\begin{array}{c}0.006 \\
(0.024)\end{array}$ \\
\hline Current health problems & $\begin{array}{l}-0.008 \\
(0.004)\end{array}$ & $\begin{array}{l}-0.013 \\
(0.012)\end{array}$ & $\begin{array}{l}-0.030 \\
(0.005)\end{array}$ & $\begin{array}{l}-0.003 \\
(0.005)\end{array}$ \\
\hline $\begin{array}{l}\text { Observations } \\
\text { No. of mothers }\end{array}$ & $\begin{array}{l}82,469 \\
11,874\end{array}$ & $\begin{array}{l}78,038 \\
11,598\end{array}$ & $\begin{array}{l}71,702 \\
10.559\end{array}$ & $\begin{array}{c}51,532 \\
8,863\end{array}$ \\
\hline Outcome mean & 0.651 & 1.841 & 5.810 & 0.635 \\
\hline Outcome standard deviation & 0.476 & 1.490 & 0.690 & 0.481 \\
\hline Kleibergen-Paap statistic & 126 & 113.1 & 137.9 & 87.67 \\
\hline
\end{tabular}

Notes: Specifications in Panel A are the baseline results presented in Table 5, and include mother-child fixed effects, child's age dummies, child health, mother's general health, mother's mental health, the number of children in the household, whether mother is separated, and environmental triggers (noise and whether child shares the bedroom). Column (3) also includes father sleep duration. Specifications in Panel B include the same covariates but control for current health problems. The number of observations across outcomes varies due to data availability. Clustered standard errors on mother-child are in parentheses. 
Table A19. Differences in Mother's Sleep Effect by Child Age and Mother Socioeconomic Characteristics

\begin{tabular}{|c|c|c|c|c|c|c|c|c|}
\hline Sleep (hours) & \multicolumn{2}{|c|}{$\begin{array}{l}\text { Probability to work } \\
\text { (1) }\end{array}$} & \multicolumn{2}{|c|}{$\begin{array}{c}\text { Log (Hours worked) } \\
(2)\end{array}$} & \multicolumn{2}{|c|}{$\begin{array}{c}\log (\text { Income }) \\
(3) \\
\end{array}$} & \multicolumn{2}{|c|}{$\begin{array}{c}\text { Satisfied with job } \\
\text { (4) }\end{array}$} \\
\hline $\begin{array}{l}\text { Panel A: } \\
\text { Child age: below } 5\end{array}$ & 0.070 & $(0.026)$ & 0.137 & $(0.063)$ & 0.032 & $(0.012)$ & 0.035 & $(0.037)$ \\
\hline $\begin{array}{l}\text { Panel B: } \\
\text { First child } \\
\text { Not first child }\end{array}$ & $\begin{array}{c}-0.028 \\
0.073 \\
\end{array}$ & $\begin{array}{l}(0.033) \\
(0.027) \\
\end{array}$ & $\begin{array}{c}-0.064 \\
0.194 \\
\end{array}$ & $\begin{array}{l}(0.095) \\
(0.079) \\
\end{array}$ & $\begin{array}{c}-0.044 \\
0.107 \\
\end{array}$ & $\begin{array}{l}(0.030) \\
(0.021) \\
\end{array}$ & $\begin{array}{r}-0.045 \\
0.020 \\
\end{array}$ & $\begin{array}{l}(0.052) \\
(0.044) \\
\end{array}$ \\
\hline $\begin{array}{l}\text { Panel C: } \\
\text { Mother: A-level } \\
\text { Mother: no A level }\end{array}$ & $\begin{array}{c}-0.056 \\
0.089 \\
\end{array}$ & $\begin{array}{l}(0.042) \\
(0.025) \\
\end{array}$ & $\begin{array}{c}-0.230 \\
0.263 \\
\end{array}$ & $\begin{array}{l}(0.124) \\
(0.073)\end{array}$ & $\begin{array}{l}0.073 \\
0.093\end{array}$ & $\begin{array}{l}(0.028) \\
(0.023)\end{array}$ & $\begin{array}{c}0.042 \\
-0.015\end{array}$ & $\begin{array}{l}(0.050) \\
(0.049)\end{array}$ \\
\hline $\begin{array}{l}\text { Panel D: } \\
\text { Self-employed } \\
\text { Not self-employed }\end{array}$ & $\begin{array}{l}0.072 \\
0.045 \\
\end{array}$ & $\begin{array}{l}(0.052) \\
(0.022) \\
\end{array}$ & $\begin{array}{l}0.129 \\
0.132 \\
\end{array}$ & $\begin{array}{l}(0.162) \\
(0.064) \\
\end{array}$ & $\begin{array}{l}0.109 \\
0.095 \\
\end{array}$ & $\begin{array}{l}(0.041) \\
(0.019) \\
\end{array}$ & $\begin{array}{r}-0.017 \\
0.005 \\
\end{array}$ & $\begin{array}{l}(0.068) \\
(0.039) \\
\end{array}$ \\
\hline $\begin{array}{l}\text { Panel E: } \\
\text { Organised } \\
\text { Not organised }\end{array}$ & $\begin{array}{r}-0.017 \\
0.023\end{array}$ & $\begin{array}{l}(0.046) \\
(0.033)\end{array}$ & $\begin{array}{l}0.002 \\
0.090\end{array}$ & $\begin{array}{l}(0.136) \\
(0.097)\end{array}$ & $\begin{array}{l}0.130 \\
0.195\end{array}$ & $\begin{array}{l}(0.036) \\
(0.034)\end{array}$ & $\begin{array}{c}0.041 \\
-0.064\end{array}$ & $\begin{array}{l}(0.062) \\
(0.056)\end{array}$ \\
\hline
\end{tabular}

Notes: Panels A, B, C, D and E report the results of separate regressions w.r.t child age, whether child is the first child or not, mother educational level, whether the mother is self-employed, and organised. All specifications are estimated using 2SLS and include mother-child fixed effects, child's age dummies, child health, mother's general health, mother's mental health, the number of children in the household, whether mother is separated, and environmental triggers (noise and whether child shares the bedroom). Specifications in column (3) also include father's sleep duration. The number of observations across outcomes varies due to data availability. Clustered standard errors on mother-child are in parentheses. 
Table A20. Effect of the Employment Rights Act 1996 on Mother Sleep and Economic Performance (Placebo test)

\begin{tabular}{|c|c|c|c|c|}
\hline & $\begin{array}{l}\text { Probability to } \\
\text { work } \\
\text { (1) } \\
\end{array}$ & $\begin{array}{c}\text { Log } \\
\text { (Hours worked) } \\
(2) \\
\end{array}$ & $\begin{array}{c}\text { Log } \\
\text { (HH income) } \\
(3) \\
\end{array}$ & $\begin{array}{c}\text { Satisfied with } \\
\text { job } \\
(4) \\
\end{array}$ \\
\hline Post $\times$ Eligible $\times$ Sleep $($ hours $)-3$ years prior & $\begin{array}{c}0.006 \\
(0.004)\end{array}$ & $\begin{array}{c}0.015 \\
(0.013)\end{array}$ & $\begin{array}{c}0.012 \\
(0.004)\end{array}$ & $\begin{array}{c}0.004 \\
(0.013)\end{array}$ \\
\hline Post $\times$ Eligible $\times$ Sleep $($ hours $)-2$ years prior & $\begin{array}{l}-0.001 \\
(0.003)\end{array}$ & $\begin{array}{c}-0.004 \\
(0.010)\end{array}$ & $\begin{array}{c}0.014 \\
(0.004)\end{array}$ & $\begin{array}{c}0.008 \\
(0.008)\end{array}$ \\
\hline Post $\times$ Eligible $\times$ Sleep $($ hours $)-1$ year prior & $\begin{array}{c}-0.004 \\
(0.003)\end{array}$ & $\begin{array}{c}-0.015 \\
(0.008)\end{array}$ & $\begin{array}{c}0.008 \\
(0.003)\end{array}$ & $\begin{array}{c}-0.001 \\
(0.004)\end{array}$ \\
\hline $\begin{array}{l}\text { Observations } \\
\text { No. of mothers } \\
\text { Outcome mean } \\
\text { Outcome standard deviation }\end{array}$ & $\begin{array}{c}58,732 \\
11,768 \\
0.488 \\
0.499 \\
\end{array}$ & $\begin{array}{c}54,494 \\
11,591 \\
1.280 \\
1.483 \\
\end{array}$ & $\begin{array}{c}49,322 \\
9,878 \\
5.639 \\
0.662 \\
\end{array}$ & $\begin{array}{c}26,204 \\
6,855 \\
0.650 \\
0.476 \\
\end{array}$ \\
\hline
\end{tabular}

Notes: Specifications are estimated using OLS, and include the same covariates as in Table 6, except that the postreform variable has been replaced by lags and leads before and after the reform. The sample is restricted to years 1991-1997. The number of observations across outcomes varies due to data availability. Clustered standard errors on mother-child are in parentheses. 
Table A21: Effect of the Employment Rights Act 1996 on Father Sleep and Mother Economic Performance (Placebo test)

\begin{tabular}{|c|c|c|c|c|}
\hline & $\begin{array}{l}\text { Probability to } \\
\text { work } \\
(1) \\
\end{array}$ & $\begin{array}{c}\log \\
\text { (Hours worked) } \\
(2) \\
\end{array}$ & $\begin{array}{c}\text { Log } \\
\text { (HH income) } \\
(3) \\
\end{array}$ & $\begin{array}{c}\text { Satisfied with job } \\
(4) \\
\end{array}$ \\
\hline Sleep(hours) & $\begin{array}{c}0.008 \\
(0.004)\end{array}$ & $\begin{array}{c}0.019 \\
(0.011)\end{array}$ & $\begin{array}{c}0.001 \\
(0.002)\end{array}$ & $\begin{array}{l}-0.002 \\
(0.007)\end{array}$ \\
\hline Eligible $\times$ Sleep(hours) & $\begin{array}{c}0.003 \\
(0.008)\end{array}$ & $\begin{array}{c}0.008 \\
(0.019)\end{array}$ & $\begin{array}{l}-0.002 \\
(0.003)\end{array}$ & $\begin{array}{l}-0.009 \\
(0.007)\end{array}$ \\
\hline Post & $\begin{array}{c}0.108 \\
(0.011)\end{array}$ & $\begin{array}{c}0.448 \\
(0.091)\end{array}$ & $\begin{array}{c}0.040 \\
(0.006)\end{array}$ & $\begin{array}{c}0.202 \\
(0.057)\end{array}$ \\
\hline Post $\times$ Sleep(hours) & $\begin{array}{c}0.003 \\
(0.004)\end{array}$ & $\begin{array}{c}0.002 \\
(0.010)\end{array}$ & $\begin{array}{c}0.004 \\
(0.005)\end{array}$ & $\begin{array}{c}0.001 \\
(0.004)\end{array}$ \\
\hline Post $\times$ Eligible & $\begin{array}{c}0.425 \\
(0.007)\end{array}$ & $\begin{array}{c}0.695 \\
(0.016)\end{array}$ & $\begin{array}{c}0.034 \\
(0.007)\end{array}$ & $\begin{array}{l}-0.001 \\
(0.006)\end{array}$ \\
\hline Post $\times$ Eligible $\times$ Sleep $($ hours $)$ & $\begin{array}{c}-0.001 \\
(0.007)\end{array}$ & $\begin{array}{c}-0.008 \\
(0.014)\end{array}$ & $\begin{array}{c}-0.004 \\
(0.007)\end{array}$ & $\begin{array}{c}0.003 \\
(0.005)\end{array}$ \\
\hline Observations & 48,099 & 44,689 & 45,466 & 22,675 \\
\hline No. of mothers & 10,251 & 10,047 & 9,426 & 6,190 \\
\hline Outcome mean & 0.488 & 1.280 & 5.639 & 0.650 \\
\hline Outcome standard deviation & 0.499 & 1.483 & 0.662 & 0.476 \\
\hline
\end{tabular}

Notes: All specifications are estimated using OLS and include child's age dummies, child's health, mother's general health, mother's mental health, the number of children in the household, and whether mother is separated. Column (3) also includes father's sleep duration. The sample is restricted to years 1991-1997. The number of observations across outcomes varies due to data availability. Clustered standard errors on mother-child are in parentheses. 


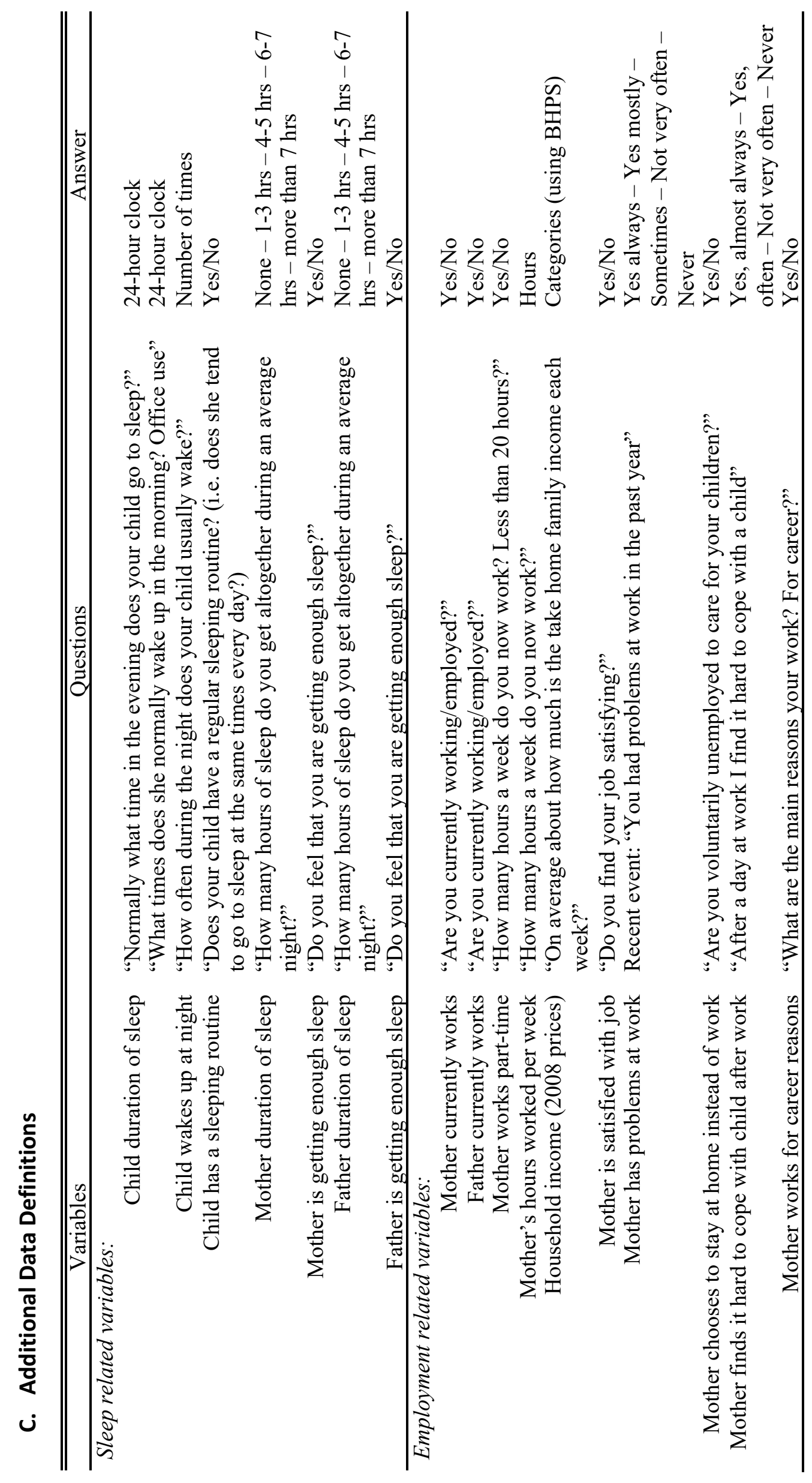




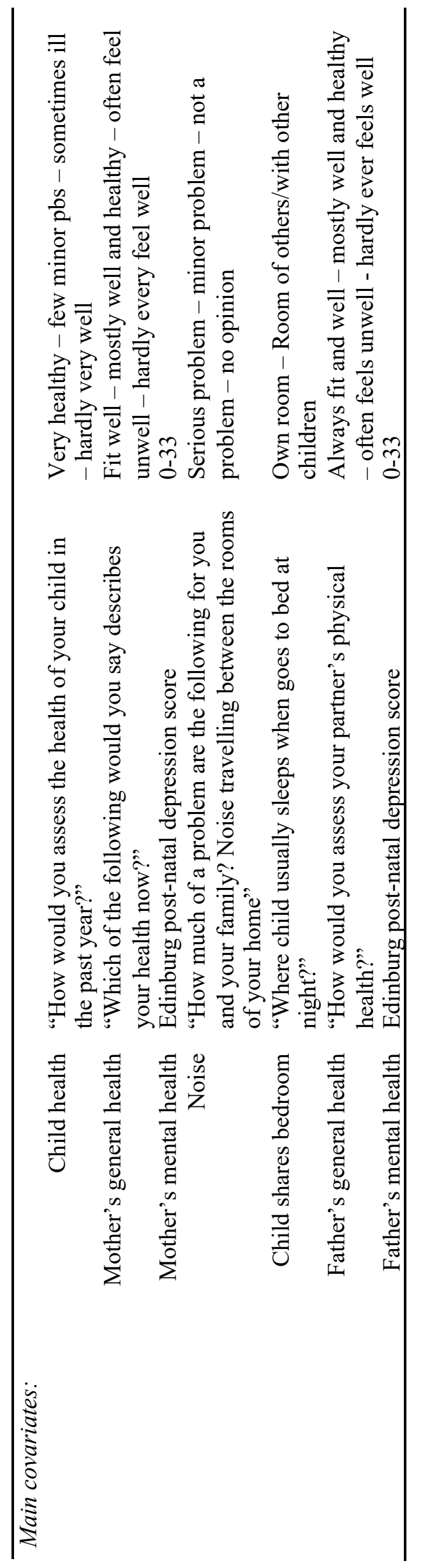

